\title{
Investigation of zinc oxide particles in cosmetic products by means of centrifugal and asymmetrical flow field-flow fractionation
}

\author{
Vanessa Sogne $^{\mathrm{a}, \mathrm{b}}$, Florian Meier ${ }^{\mathrm{b}}$, Thorsten Klein ${ }^{\mathrm{b}}$, Catia Contado ${ }^{\mathrm{a}, *}$ \\ ${ }^{a}$ University of Ferrara, Department of Chemical and Pharmaceutical Sciences, via L. Borsari, 46, 44121 Ferrara, Italy \\ b Postnova Analytics GmbH, Max-Planck-Straße 14, 86899 Landsberg am Lech, Germany
}

\section{A R T I C L E I N F O}

\section{Article history}

Received 2 May 2017

Received in revised form 27 July 2017

Accepted 31 July 2017

Available online $\mathrm{xxx}$

Keywords:

$\mathrm{ZnO}$ particles

Centrifugal FFF

Asymmetrical flow FFF

Cosmetic products

Particle extraction

Particle sizing

Sample preparation

\begin{abstract}
A B S T R A C T
The dimensional characterization of insoluble, inorganic particles, such as zinc oxide $\mathrm{ZnO}$, dispersed in cosmetic or pharmaceutical formulations, is of great interest considering the current need of declaring the possible presence of nanomaterials on the label of commercial products

This work compares the separation abilities of Centrifugal- and Asymmetrical Flow Field-Flow Fractionation techniques (CF3 and AF4, respectively), equipped with UV-vis, MALS and DLS detectors, in size sorting $\mathrm{ZnO}$ particles, both as pristine powders and after their extraction from cosmetic matrices.

$\mathrm{ZnO}$ particles, bare and superficially modified with triethoxycaprylyl silane, were used as test materials. To identify the most suitable procedure necessary to isolate the $\mathrm{ZnO}$ particles from the cosmetic matrix, two $\mathrm{O} / \mathrm{W}$ and two W/O emulsions were formulated on purpose. The suspensions, containing the extracted particles $\mathrm{ZnO}$, were separated by both Field-Flow Fractionation (FFF) techniques to establish a common analysis protocol, applicable for the analysis of $\mathrm{ZnO}$ particles extracted from three commercial products, sold in Europe for the baby skin care.

Key aspects of this study were the selection of an appropriate dispersing agent enabling the particles to stay in stable suspensions ( $>24 \mathrm{~h}$ )and the use of multiple detectors (UV-Vis, MALS and DLS) coupled on-line with the FFF channels, to determine the particle dimensions without using the retention parameters. Between the two FFF techniques, CF3 revealed to be the most robust one, able to sort all suspensions created in this work.
\end{abstract}

\section{Introduction}

Zinc oxide $(\mathrm{ZnO})$ is a versatile material used in many productive sectors, of which the rubber application accounted for the largest market share, followed by ceramics, chemicals, pharmaceuticals, cosmetics, personal care and agricultural products. $\mathrm{ZnO}$ has key applications in catalysts, sensors, piezoelectric transducers, transparent conductor and surface acoustic wave devices [1], in paints [2,3] and surface coatings [4] as white pigment with antibacterial and long term UV blocking properties. Its antibacterial, antimicrobial, disinfecting and drying properties make the $\mathrm{ZnO}$ also suitable for pharmaceutical products, mostly as ointments and creams [5]. In the cosmetic sector, $\mathrm{ZnO}$ is used as a colorant or bulking agent, in sunscreens as UV-blocker, but also as a soothing and protective coating against skin irritation and abrasion. In the food industry, $\mathrm{ZnO}$ is incorporated in polymeric matrices to provide antimicrobial activity to the packaging material and improve packaging properties [6] but it can be also found as UV light absorber inside of unplasticised polymers used for

\footnotetext{
* Corresponding author.

Email addresses: florian.meier@postnova.com (F. Meier); catia.contado@unife.it (C. Contado)
}

long-term storage at room temperature. The recent increase of nano-materials to enhance the quality of many products has determined the revision of many existing international regulations in the cosmetic and food sectors. The European Union (EU) Commission's Working Group on Cosmetics, for example, in 2016, on the basis of comprehensive safety dossiers, stated that in dermal cosmetic products $\mathrm{ZnO}$ might be used in its nano-form up to the $25 \%$ without posing risk for adverse health effects in humans [7,8]. However, $\mathrm{ZnO}$ nanoparticles (NPs) shall not be used in spray products (e.g. disinfectant spray is declared unsafe) since this may lead to exposure of the consumers' lungs due to inhalation [8]. If used for dermal application, ZnO NPs must have a median diameter of the particle number size distribution D50 (50\% of the number below this diameter) $>30 \mathrm{~nm}$ and D1 $(1 \%$ below this size) $>20 \mathrm{~nm}$ [8]. The U.S. F.D.A. lists $\mathrm{ZnO}$ as a "generally recognized as safe" (GRAS) material and allows it as food additive [9], authorising its use in food contact materials (up to $2 \%$ by weight) when used in its nano-form [10]. However, its risk assessment must include studies on some aspects of the behaviour of the nano-preparations, since the toxicity of metal-based NPs may be either due to the specific toxicity of metal ions released from NPs under environmental conditions or to their specific physical characteristics as NPs. 
The size analysis of $\mathrm{ZnO}$ particles dispersed in cosmetic (or pharmaceutical) formulations is consequently now an important task that analytical methods should face [11], since they could be used to discriminate the presence of particles in the nano and/or micro form. This implies that the analytical methods should be able to determine the particle size distribution or at least to contribute, for example through a separation, to its determination.

Tyner et al. [12] compared the ability of 20 analytical methods to detect and size $\mathrm{TiO}_{2}$ and $\mathrm{ZnO}$ NPs in unmodified commercial sunscreens, with the aim to find appropriate analytical methods able to perform this characterization without the introduction of any significant product modifications. The most studied cosmetic matrices so far are sunscreen products, since their dermal application implies the exposition of $\mathrm{ZnO}$ and $\mathrm{TiO}_{2}$ particles to the UV radiation, which may induce photocatalytic activity and generate DNA-damaging reactive oxygen species [13]. There are a number of analytical methods that might be used to size particles [14] and to support the electron microscopy, which is recommended by the SCCS (Guidelines on the safety assessment of nanomaterials) [15], such as variable-pressure scanning electron microscopy, atomic force microscopy (AFM), laser scanning confocal microscopy (LSCM), and X-ray diffraction (XRD) [16]. In many cases, the determination of the average particle size and the size distribution of particles incorporated in cosmetic products, require a preliminary extraction step [17-19].

To date and to the authors' best knowledge, no reports on a systematic comparison and optimisation of extraction conditions for a reliable size characterisation of $\mathrm{ZnO}$ particles in real cosmetic matrices, using Field-Flow Fractionation (FFF) techniques coupled online with different detectors have been published.

This work consequently has two main aims, to study whether and how the extraction procedures should differ depending on the cosmetic matrices and to compare the separation performances of two FFF techniques, Centrifugal FFF (CF3) and Asymmetrical Flow FFF (AF4), both used for particle size characterization.

Both CF3 and AF4 instruments are suitable to sort particles and colloids of different nature [20], depending on their buoyant mass (CF3) or on the hydrodynamic particle dimension (AF4), respectively. Here, their separation performances are evaluated by analysing (i) two different types of pristine, powdered $\mathrm{ZnO}$ particles, bare and superficially modified with triethoxycaprylyl silane, available on the market to formulate cosmetic products, (ii) four cosmetic creams formulated in-house, and (iii) three cosmetic commercial cosmetic products, sold in Italy and Germany for baby skin care when nappy rush occurs.

The extraction procedures of the particles were evaluated in order to get stable suspensions (at least $24 \mathrm{~h}-48 \mathrm{~h}$ ), without irreversibly altering their original particle size distribution. The comparison between the pre- and post-formulation was possible since two $\mathrm{O} / \mathrm{W}$ emulsions and two $\mathrm{W} / \mathrm{O}$ emulsions were prepared on purpose, by adding respectively the uncoated or the coated $\mathrm{ZnO}$ particles as ingredients. This is an important difference with respect to past works, in which, for example, food matrices were simply spiked with inorganic $\mathrm{NPs}\left(\mathrm{SiO}_{2}\right.$ $[21,22]$, silver NPs $[23,24])$.

The suspensions of the extracted $\mathrm{ZnO}$ particles were separated via CF3 and AF4 techniques and the separation profiles were compared with those obtained from the pristine $\mathrm{ZnO}$ powders. Although these techniques allow the determination of the buoyant mass (CF3) or the hydrodynamic dimension of the particles (AF4), based on their retention behaviour in the respective separation channel [20], information about the sizes were obtained by equipping the instruments with a series of on-line detectors (UV-vis, MALS, DLS) able to derive size information independently from the retention data.
The separation results of the $\mathrm{ZnO}$ particles extracted from the in-house formulated creams were used to hypothesize and verify the most suitable protocols to extract and analyse by FFF the $\mathrm{ZnO}$ particles contained in the unknown commercial creams by FFF.

\section{Experimental}

\subsection{Samples}

Zinc oxide powders, Zano10 and Zano10 Plus, were kindly donated by Prodotti Gianni Srl (Milan, I), the Italian retailer of Umicore (Luik, B). The certificate of analysis of the Zano10 Plus (Lot \#Z1P264), reports a triethoxycaprylyl silane surface treatment level of $4.0 \% \mathrm{wt}$.

Four cosmetic emulsions, nominally containing $20 \%$ wt of $\mathrm{ZnO}$ were formulated on purpose for this study. They were oil-in-water $(\mathrm{O} /$ $\mathrm{W})$ and water-in-oil $(\mathrm{W} / \mathrm{O})$ emulsions; those containing the Zano10 particles were named $\mathrm{F} 1(\mathrm{O} / \mathrm{W})$ and $\mathrm{F} 2(\mathrm{~W} / \mathrm{O})$, while those based on Zano10 Plus were F3 (O/W) and F4 (W/O) (Table 1). The list of the ingredients used to formulate the emulsions and details about their preparation are reported in the Supp. Mat. $\S$ S-2.

Three commercial products, two creams and a paste enriched with zinc oxide, were purchased in Italian and German grocery shops. The products were indicated as CS-1 (W/O), CS-2 (W/O), CS-3 (O/W) (Tables 1 and S-1).

A summary of the samples analysed by CF3 and AF4 is reported in Table 1 .

\subsection{Chemicals}

All chemicals $\left(\mathrm{CH}_{3} \mathrm{COOH} 96 \%\right.$ premium grade, $\mathrm{HNO}_{3} 65 \%$ suprapure, $\mathrm{H}_{3} \mathrm{BO}_{3} 99.97 \%$ trace metal basis, $\mathrm{HCl} 1 \mathrm{M}$; KCl, NaOH $1 \mathrm{M}$, $\mathrm{NH}_{3} 25 \%$ ) were purchased from Sigma Aldrich (St. Louis, MO, USA) or Merck (Darmstadt, D); $n$-hexane for HPLC (ChemSolute - Th. Geyer, Renningen, D), ethanol $\mathrm{C}_{2} \mathrm{H}_{6} \mathrm{O}$ 99.5\% (Bernd Kraft GmbH, Duisburg, D); $\mathrm{H}_{2} \mathrm{O}_{2} 30 \%$ RPE (Carlo Erba, Milan, I), ultra-pure SDS sodium dodecyl sulfate (Carl Roth, Karlsruhe, D), NovaChem (NC) Surfactant 100 (Postnova Analytics GmbH, Landsberg am Lech, D).

The ultrapure water (UPW) used in this study was prepared by using a Milli-Q integral 5 Millipore system (EMD Merck Millipore, MA, USA), with subsequent vacuum filtration through a $0.1 \mu \mathrm{m}$ pore membrane (Durapore, Millipore).

A polystyrene (PS) latex-mixture dispersed in $0.2 \% \mathrm{v} / \mathrm{v} \mathrm{NC}$ was used for size calibration of MALS detectors. CF3-MALS: PS $200 \mathrm{~nm}$, $300 \mathrm{~nm}$ and $600 \mathrm{~nm}$; AF4-MALS: PS $125 \mathrm{~nm}, 200 \mathrm{~nm}$ and $300 \mathrm{~nm}$ (Postnova Analytics GmbH).

Table 1

Summary of the sample' characteristics. The nominal content of $\mathrm{ZnO}$ in the model emulsions was $20 \%$ wt for all formulations.

\begin{tabular}{|c|c|c|c|c|}
\hline $\begin{array}{l}\text { Sample or } \\
\text { formulation name }\end{array}$ & Sample type & $\mathrm{ZnO}$ type & $\begin{array}{l}\text { Emulsion } \\
\text { type }\end{array}$ & $\begin{array}{l}\mathrm{ZnO} \text { added in } \\
\text { the external }\end{array}$ \\
\hline Zano10 - powder & Model & Bare & - & - \\
\hline $\begin{array}{l}\text { Zano10 Plus - } \\
\text { powder }\end{array}$ & Model & $\begin{array}{l}\text { Superficially } \\
\text { coated }\end{array}$ & - & - \\
\hline $\mathrm{F} 1(\mathrm{O} / \mathrm{W})$ & Model & Zanol0 & $\mathrm{O} / \mathrm{W}$ & organic phase \\
\hline $\mathrm{F} 2(\mathrm{~W} / \mathrm{O})$ & Model & Zano10 & $\mathrm{W} / \mathrm{O}$ & aqueous phase \\
\hline $\mathrm{F} 3(\mathrm{O} / \mathrm{W})$ & Model & Zano10 Plus & $\mathrm{O} / \mathrm{W}$ & organic phase \\
\hline $\mathrm{F} 4(\mathrm{~W} / \mathrm{O})$ & Model & Zano10 Plus & $\mathrm{W} / \mathrm{O}$ & aqueous phase \\
\hline CS-1 & Commercial & & $\mathrm{W} / \mathrm{O}$ & unknown \\
\hline $\mathrm{CS}-2$ & Commercial & & $\mathrm{W} / \mathrm{O}$ & unknown \\
\hline CS-3 & Commercial & & $\mathrm{O} / \mathrm{W}$ & unknown \\
\hline
\end{tabular}


Quantification via ICP-MS and ICP-OES was performed using element standard solutions containing Zn $\left(10 \mu \mathrm{gmL}^{-1}-\right.$ Environmental Calibration Standard, Agilent Technologies) and $\left(1000 \mathrm{mgL}^{-1}-\mathrm{mo-}\right.$ noelement standard solution, Carlo Erba), respectively.

\subsection{Instruments}

\subsection{1. $C F 3$}

Channel dimensions of the applied CF2000 Centrifugal FFF (Postnova Analytics $\mathrm{GmbH}, \mathrm{D})$ were as follows: channel length $57.6 \mathrm{~cm}$, width $2 \mathrm{~cm}$, thickness $250 \mu \mathrm{m}$ (void volume $2.7 \mathrm{~mL}$ ), with a radius of $10.2 \mathrm{~cm}$. The system was equipped with a solvent degasser (PN 7520), an isocratic pump (PN 1130), an autosampler (PN 5300 - $20 \mu \mathrm{L}$ injection volume), a Multi-Angle Light Scattering MALS Detector (PN 3621) and an UV-vis Detector (PN 3211 SPD-20A). The MALS signal was recorded at 21 different angles of which 17 angles showing the best fit with the applied random coil model (all available angles except for $7^{\circ}, 12^{\circ}, 156^{\circ}$ and $164^{\circ}$ ) were used for the determination of the radii of gyration $\left(r_{g}\right)$. Values for $r_{g}$ were calculated from measured signal intensities by application of the following intensity distribution function $P(\vartheta)$ :

$$
P(\vartheta)=\frac{2}{h^{4}}\left(e^{-h^{2}}-1+h^{2}\right)
$$

with

$$
h=\frac{4 \pi \eta r_{g}}{\lambda} \sin \frac{\vartheta}{2}
$$

$P$ represents the scattering form factor describing the angular dependence of the intensity of the scattered light, $\vartheta$ the respective observed angle, $\eta$ the refractive index of the solvent, $r_{g}$ the radius of gyration and $\lambda$ the wavelength of the incident laser light. Calculations were performed using the Postnova AF2000 software. The wavelength of the laser beam was $532 \mathrm{~nm}$, while the wavelength of the UV-vis was set at $380 \mathrm{~nm}$. The eluent was prepared using UPW to which $0.2 \%$ $\mathrm{v} / \mathrm{v}$ filtered $\mathrm{NC}$ was added. The flow rate was $0.5 \mathrm{mLmin}^{1}$ and the separations were performed by applying a programmed power field decay [20]; parameters are reported in Table 2.

\subsubsection{AF4}

The trapezoidal channel of the applied AF2000 Flow FFF (Postnova Analytics $\mathrm{GmbH}, \mathrm{D}$ ) had the following main dimensions: channel breadth to the inlet $2 \mathrm{~cm}$, breadth to the outlet $0.5 \mathrm{~cm}$, channel length $27.7 \mu \mathrm{m}$ (tip-to-tip), nominal channel thickness $350 \mu \mathrm{m}$; nomi- nal channel volume $1.147 \mathrm{~mL}$. The accumulation wall was a $10 \mathrm{kDa}$ regenerated cellulose membrane (Z-AF4 MEM-635-10KD); the spacer was made of Mylar. The AF4 system was equipped with a solvent degasser (PN 7520), an isocratic pump (PN 1130), an autosampler (PN5300 - 20 $\mu \mathrm{L}$ injection volume), a channel thermostat (PN4020) and two different detectors: MALS detector (PN3621, 21 angles) and an UV-vis Detector (PN3211 SPD-20A). Determination of $r_{g}$ values via MALS was performed as described under 3.2.1, In this case, the best fit with the applied random coil model was achieved by evaluating 18 angles (all available angles except for $7^{\circ}, 12^{\circ}$ and $20^{\circ}$ ). In order to allow a direct comparison with the results obtained from CF3-UV-MALS, $r_{g}$ values were also determined with a similar selection of angles as described for the CF3-UV-MALS setup, without observing significant differences between the $r_{g}$ values. Examples of fitting curves for the applied random coil model for both FFF-UV-MALS setups are given in Fig. S-1. In analogy to the CF3-UV-MALS setup, the wavelength of the laser beam was $532 \mathrm{~nm}$, while the wavelength of the UV-vis was set at $380 \mathrm{~nm}$. The eluent was a $0.2 \% \mathrm{v} / \mathrm{v}$ NC solution and the separations were performed by applying a programmed field decay [25], whose parameters are reported in Table 2 .

\subsection{3. $D L S$}

A Zetasizer Nano-ZS instrument (Malvern Instruments Ltd, UK) with temperature control was used to determine the particle size distribution (PSD) by Dynamic Light Scattering (DLS). The measurements were done at $24.9-25.0^{\circ} \mathrm{C}$, using a DTS0012 cuvette. Each sample was measured in duplicate with an equilibration step of $120 \mathrm{~s}$ and an acquisition time of $80 \mathrm{~s}$. The software automatically calculated the hydrodynamic diameters based on the Stokes-Einstein theory. The instrument also allowed the determination of the $\zeta$-potential by using a DTS1060C disposable cell and setting an equilibration time of $120 \mathrm{~s}$. The measurements were done immediately after having measured the $\mathrm{pH}$; the Smoluchowski model with a Henry's Function $\mathrm{F}(\mathrm{Ka})$ of 1.5 was used to determine the $\zeta$-potential.

\subsubsection{Other instruments}

An Perkin-Elmer Optima 3100 XL inductively coupled plasma optical emission spectrometer (ICP-OES) and an Agilent 7900 inductively coupled plasma mass spectrometer (ICP-MS) were used to determine the element $(\mathrm{Zn})$ concentration. Details of these instruments are given in the Supp.Mat. $\S$ S-3 and $\S$ S-4.

\subsection{Methods}

\subsubsection{Determination of the zeta potential}

$1 \mathrm{mg} \mathrm{mL} \mathrm{m}^{-1}$ of $\mathrm{ZnO}$ powder was dispersed in $1 \mathrm{mM} \mathrm{KCl}$, adjusting the $\mathrm{pH}$ with $\mathrm{HNO}_{3}$ or $\mathrm{NaOH}$ in the range of 3-11. The $\mathrm{ZnO}$ isoelec-

Table 2

\begin{tabular}{|c|c|c|c|}
\hline CF3 & $\rightarrow$ & AF4 & \\
\hline Field equation: (filed type: exponential) & $G=G_{0}\left(\frac{t_{1}-t_{a}}{t-t}\right)^{p}$ & Field equation (field type: exponential) & $F_{\text {cross }}=F_{\text {cross }}^{\text {start }}-\left(F_{\text {cross }}^{\text {start }}-F_{\text {cross }}^{\text {end }}\right)\left(\frac{t}{t}\right)^{n}$ \\
\hline Tip flow ${ }^{(1)}\left(\mathrm{mL} \min ^{-1}\right)$ & 0.5 & Injection flow $\left(\mathrm{mL} \mathrm{min}^{-1}\right)$ & 0.2 \\
\hline Injection time (min) & 2.4 (autosampler)) & Injection time (min) & 7 \\
\hline Focusing time (min) & 8 & Focusing time (min) & 2 \\
\hline Exponent $(p)$ & 8 & Exponent $(n)$ & 0.2 \\
\hline Initial Field (RPM) & 1000 & $F_{\text {cross }}^{\text {start }}\left(\mathrm{mL} \mathrm{\operatorname {min } ^ { - 1 } )}\right.$ & 1 \\
\hline Delay time before decay $t_{l}$ (min) & 20 & Duration of the cross flow gradient $t_{\text {end }}(\mathrm{min})$ & 105 \\
\hline Second time parameter $t_{a}(\mathrm{~min})$ & -55 & & \\
\hline Final field (RPM) & 60 & $F_{\text {cross }}^{\text {end }}\left(\mathrm{mL} \mathrm{min}{ }^{-1}\right)$ & 0.1 \\
\hline
\end{tabular}

Field parameters of CF3 and AF4. Sample concentration $1 \mathrm{mg} \mathrm{mL}^{-1}$. Injection volume $20 \mu \mathrm{L}$. UV-vis wavelength $\lambda=380 \mathrm{~nm}$. Eluent $0.2 \% \mathrm{v} / \mathrm{v}$ NC. ZnO density $5.4 \mathrm{~g} \mathrm{~cm}^{-3}$ 
tric point (i.e.p.) was measured with a DLS Zetasizer Nano ZSP on 9 suspensions after having sonicated them in an ultrasonic bath (USB Sonorex digital 10P, Bandelin Electronic GmbH \& Co. KG, Berlin, D) at maximum power for $60 \mathrm{~min}$. During ultrasonication, ice packs were added to the water bath to keep water temperature under control.

\subsubsection{Extraction of the $\mathrm{ZnO}$ particles from the hydrophilic emulsions: $\mathrm{F} 1(\mathrm{O} / \mathrm{W})$ and $\mathrm{F3}(\mathrm{O} / \mathrm{W})$}

Method A: $0.05 \mathrm{~g}$ of cream, nominally containing $20 \%$ wt of $\mathrm{ZnO}$, (either Zano10 or Zano10 Plus) was mixed with $10 \mathrm{~mL}$ of UPW (1 $\mathrm{mgmL}^{-1}$ of $\mathrm{ZnO}$ ) and sonicated in an ultrasonic bath (USB Sonorex digital 10P) at the highest power for $15 \mathrm{~min}$. The suspension was divided in two aliquots of $5 \mathrm{~mL}$ each. $5 \mathrm{~mL}$ of $n$-hexane were added to the 2 aqueous suspensions and vigorously mixed for $30 \mathrm{~s}$. The suspensions were then centrifuged at $10,000 \mathrm{rpm}$ for $5 \mathrm{~min}$. The organic phase was removed and replaced with $5 \mathrm{~mL}$ of pure $n$-hexane. The suspensions were subsequently sonicated for $15 \mathrm{~min}$ and again centrifuged at 10,000 rpm for $5 \mathrm{~min}$. The organic phase was removed from the first aliquot, which was successively used "as is" for the FFF separations ( $\mathrm{ZnO}$ dispersed in UPW). The second aliquot was emptied from both liquid phases, organic and aqueous, and the sediment was re-dispersed in $0.5 \% \mathrm{v} / \mathrm{v} \mathrm{NC} \mathrm{(} \mathrm{ZnO}$ dispersed in $\mathrm{NC})$. The two aqueous suspensions were sonicated for $45 \mathrm{~min}$ in the USB before FFF measurements.

Method B: $0.05 \mathrm{~g}$ of cream, nominally containing $20 \%$ wt of $\mathrm{ZnO}$, (either Zano10 or Zano10 Plus) was dissolved in $10 \mathrm{~mL}$ of $n$-hexane/ ethanol $(2: 1)\left(1 \mathrm{mgmL}^{-1}\right.$ of $\left.\mathrm{ZnO}\right)$. The suspension was centrifuged for $10 \mathrm{~min}$ at $13,000 \mathrm{rpm}$. The sediment was separated from the organic phase and treated with a new aliquot of $n$-hexane/ethanol. To efficiently re-suspend the sediment in the organic phase, the suspension was subsequently sonicated for $10 \mathrm{~min}$ in the USB. After the centrifugation (10 min at 13,000 rpm), the organic solvent was removed and the sediment was divided in two portions, re-suspended in UPW and in $0.5 \% \mathrm{v} / \mathrm{v} \mathrm{NC}$, respectively. The two aqueous suspensions were sonicated for $45 \mathrm{~min}$ in the USB before FFF measurements.

\subsubsection{Extraction of the $\mathrm{ZnO}$ particles from the lipophilic emulsions $f 2(\mathrm{~W} / \mathrm{O})$ and $\mathrm{F} 4(\mathrm{~W} / \mathrm{O})$}

Method C: $0.5 \mathrm{~g}$ of cream, nominally containing $20 \% \mathrm{wt}$ of $\mathrm{ZnO}$ (either Zano10 or Zano10 Plus) was added to $10 \mathrm{~mL}$ of $n$-hexane $\left(10 \mathrm{mgmL}^{-1}\right.$ of $\left.\mathrm{ZnO}\right)$ and sonicated for $15 \mathrm{~min}$ in the USB. $5 \mathrm{~mL}$ of deionized water were added to the organic phase, shaken vigorously and centrifuged for $5 \mathrm{~min}$ at $10,000 \mathrm{rpm}$. The solvents were then removed and replaced with $5 \mathrm{~mL}$ of $n$-hexane and $5 \mathrm{~mL}$ of UPW. To efficiently re-suspend the sediment, the suspension was sonicated for $15 \mathrm{~min}$ in the USB, and centrifuged at $10,000 \mathrm{rpm}$ for $5 \mathrm{~min}$. After having removed the solvents, the sediment was divided in two aliquots, re-suspended in UPW and in $0.5 \% \mathrm{v} / \mathrm{v} \mathrm{NC}$, respectively. The two aqueous suspensions were sonicated for $45 \mathrm{~min}$ in the USB before FFF measurements.

Method D: $0.1 \mathrm{~g}$ of cream, containing nominally $20 \% \mathrm{wt}$ of $\mathrm{ZnO}$ (either Zano10 or Zano10 Plus) was suspended in $10 \mathrm{~mL}$ of $n$-hexane/ ethanol (2:1) $\left(2 \mathrm{mgmL}^{-1}\right.$ of $\left.\mathrm{ZnO}\right)$ and treated as described in Method B. The extraction procedure was repeated three times.

\subsubsection{Extraction of the $\mathrm{ZnO}$ particles from commercial formulations}

$0.5 \mathrm{~g}$ (CS-1 and CS-2, W/O emulsions) and $1.0 \mathrm{~g}$ (CS-3, O/W emulsion) of cream were dispersed in $50 \mathrm{~mL}$ of $n$-hexane/ethanol and allowed to stand for 2 days. The $\mathrm{W} / \mathrm{O}$ emulsions were treated according to the Method $\mathrm{D}$, while the $\mathrm{O} / \mathrm{W}$ emulsion was treated according to the Method A.

\subsubsection{Sample preparation for the SEM observations}

$\mathrm{ZnO}$ particles were suspended in a $0.1 \% \mathrm{v} / \mathrm{v} \mathrm{NC}$ solution, sonicated in an USB (Ultrasonic CP104 STD, C.E.I.A. SpA, I) for $30 \mathrm{~min}(50 \%$ of the $400 \mathrm{VA}$ max), filtered through a $0.1 \mu \mathrm{m}$ IsoporeTM membrane (Millipore-Merck), then glued onto aluminium stubs using double-adhesive tape (TAAB Laboratories Equipment, Ltd. Aldermaston, Berkshire, UK). The $\mathrm{ZnO}$ particles extracted from the commercial samples and contained in the aqueous phase were suspended in a $0.1 \% \mathrm{v} / \mathrm{v} \mathrm{NC}$ solution and treated as described above. SEM observations were done with a scanning electron microscope (ZEISS EVO 40, Carl Zeiss Microscopy $\mathrm{GmbH}, \mathrm{D})$; the accelerating voltage was $20 \mathrm{kV}$.

\subsubsection{Sample mineralization for the ICP-OES and ICP-MS analyses}

Between $0.15 \mathrm{~g}-0.20 \mathrm{~g}$ of powder or cream was carefully weighted and placed in a Teflon vessel (TFM Milestone), in which $6 \mathrm{~mL}$ of $\mathrm{HNO}_{3}$ suprapure and $1 \mathrm{~mL}$ of $\mathrm{H}_{2} \mathrm{O}_{2}$ were added. The tubes were placed in a microwave oven (Ethos 900 Milestone, rotor HPR $1000 / 6 \mathrm{M})$. Digestion of the samples was performed following the temperature program reported in Table S-2. Each vessel was then left to cool down for at least $10 \mathrm{~min}$ before adding $1.5 \mathrm{~g}$ of $\mathrm{H}_{3} \mathrm{BO}_{3}$. The vessel was then returned in the microwave for $5 \mathrm{~min}$ at $300 \mathrm{~W}$. Finally, the vessels were cooled down and the content was transferred to a $50 \mathrm{~mL}$ volumetric flask and diluted with ultrapure water to a final volume of $50 \mathrm{~mL}$. All samples, including the commercial samples, quickly dissolved producing clear and transparent final solutions. All digestions were performed in triplicates.

\section{Results \& discussion}

\subsection{Stability of the $\mathrm{ZnO}$ dispersions: choice of the suspending medium and the dispersing procedure}

The success of a separation analysis with FFF instruments strongly depends on the stability of the suspensions, which should be stable at least over the time necessary to accomplish the measurements. The interactions between $\mathrm{ZnO}$ particles in aqueous media are affected by several parameters including $\mathrm{pH}$, ionic composition and surfactants. To gain information about the surface charge of the $\mathrm{ZnO}$ particles, the Zano10 and Zano10 Plus powders were dispersed in $15 \mathrm{mM} \mathrm{KCl}$ and the $\zeta$-potential was measured as a function of $\mathrm{pH}$. The experimentally determined isoelectric points (i.e.p.) were i.e.p. $=10.0$ for the Zano10 Plus and i.e.p. $=10.2$ for the Zano10 particles (Fig. S-2a), values slightly higher than the values reported by Majedi et al. [26] (9.0) and Keller et al. [27] (9.2), but in line with those reported by other authors $[28,29]$.

The average hydrodynamic diameters of the particles, or more precisely aggregates or agglomerates, in the $\mathrm{ZnO}$ suspensions measured by DLS, were roughly $500 \mathrm{~nm}$ at $\mathrm{pH} 3-4$ and gradually increased as the $\mathrm{pH}$ approached the i.e.p. $\left(\mathrm{pH}_{\mathrm{iep}} \cong 10\right)$, thereby reaching a maximum. At pH 11, a decrease of the i.e.p. was observable, in line with the $\zeta$-potential values (Fig. S-2b) and confirming a trend also observed for other metal oxide systems [30,31]. This trend is common for suspensions, which are only stabilised electrostatically [29] and for which it is known that particles start to aggregate when the absolute value of the zeta potential decreases to less than approximately $30 \mathrm{mV}$. According to these measurements, the $\mathrm{ZnO}$ suspensions should be stable either at very low or at very high $\mathrm{pH}$ values. However, the addition of ionic dispersants or surfactants to the suspensions improve their stability since they add surface charge density on the metal oxide surface by simple surface absorption [29]. 
A series of different dispersion protocols were tested for both $\mathrm{ZnO}$ powders. They were dispersed in ultrapure water (UPW), in four aqueous buffers at different $\mathrm{pH}$ values (acetic buffer - $\mathrm{pH} 4$ and 5, ammonium buffer $-\mathrm{pH} 10$ and 11) and in presence of a surfactant $(0.2 \%$ $\mathrm{v} / \mathrm{v}$ and $0.5 \% \mathrm{v} / \mathrm{v} \mathrm{NC})$. The powder Zano10 Plus was also dispersed in $\mathrm{H}_{2} \mathrm{O} / \mathrm{MeOH} 20 \%$. The dispersions prepared in the buffer solutions were all unstable within a $24 \mathrm{~h}$-period, which is in agreement with the indication obtained from the $\zeta$-potential data. On the other hand, the $\mathrm{ZnO}$ dispersions in UPW and $0.5 \% \mathrm{NC}$ were surprisingly stable (Supp. Mat. Fig. S-3) with a pH, measured at $23{ }^{\circ} \mathrm{C}$ of $\approx 7.2$ in UPW and $10.4-10.5$ in $0.5 \% \mathrm{v} / \mathrm{v}$ NC. This latter value closely relates to the i.e.p., the measured $\zeta$-potential of this suspensions was $\cong-45.4$ $( \pm 0.5) \mathrm{mV}$, confirming a significant adsorption of surfactant molecules on the surface of the $\mathrm{ZnO}$ particles.

The suspensions here analysed and discussed were prepared in $0.5 \% \mathrm{v} / \mathrm{v} \mathrm{NC}$ and sonicated for $60 \mathrm{~min}$ in the USB each time prior to use to guarantee at least a $24 \mathrm{~h}$ stability. The treatment with the USB for $60 \mathrm{~min}$ was the most efficient dispersing procedure chosen among vortex ( $2 \mathrm{~min}$ ) and USB for 15, 30 or $60 \mathrm{~min}$. Suspensions were stored at $4{ }^{\circ} \mathrm{C}$ for a period no longer than 4 weeks to avoid bacterial contaminations and particle size modifications [32].

\section{2. $\mathrm{CF} 3$ and AF4 dimensional characterization of the $\mathrm{ZnO}$ powders}

The dimensional characterization of both $\mathrm{ZnO}$ particle suspensions (Zano10 and Zano10 Plus - $1 \mathrm{mgmL}^{-1}$ ), was accomplished by both CF3 and AF4. The separations by CF3 and AF4 were performed under programmed field conditions since the samples had very wide dimensional distributions. The field decay profile followed a "power decay" like shape, whose parameters reported in Table 2
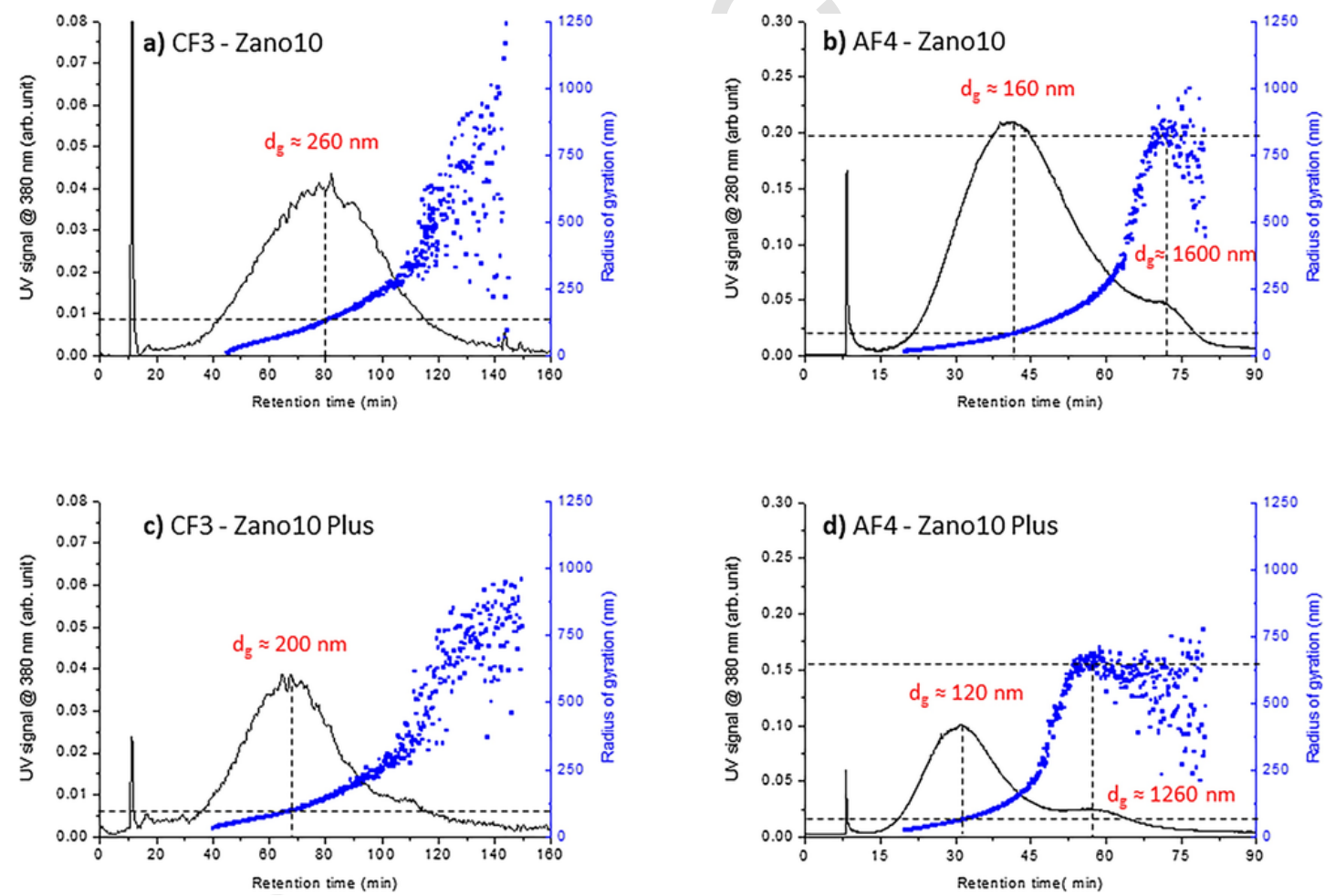

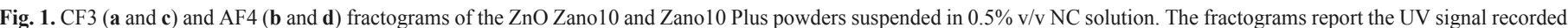

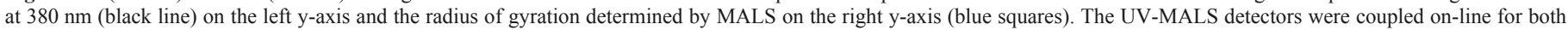

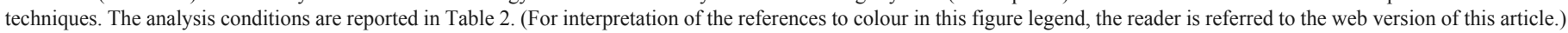

were selected after an optimisation study, aiming to have a good fractionation power $\mathrm{F}_{\mathrm{d}}\left(\mathrm{F}_{\mathrm{d}}\right.$ slowly decreasing from 6 to 2.2 for the CF3 separations [20]) in a reasonable analysis time. The fractograms were always recorded by both UV-vis and MALS detector. The eluent was a $0.2 \% \mathrm{v} / \mathrm{v} \mathrm{NC}$ solution for both techniques. All analyses were usually repeated 3-5 times to check the repeatability of the separation process, which was very high, as proven by the sequence of CF3 and AF4 fractograms perfectly overlapping shown in Fig. S-4. This systematic control allows a simplified comparison between the two techniques through graphs, which only report one fractogram as shown of Fig. 1. The CF3 separations required longer analysis times than AF4 (graphs a and c, 160 min vs 90 min - graphs b and d), independently of the type of powder suspensions. The AF4 fractograms also highlight a bimodal distribution for both Zano10 and Zano 10 Plus samples, not visible in the CF3 fractograms. This apparent discrepancy finds an explanation by observing the particle sizes, elaborated from the MALS signal and reported on the right y-axis as radius of gyration $\left(r_{g}\right)$ superimposed by the selected separation profiles, obtained from the UV detector signal at $380 \mathrm{~nm}$ (Fig. 1). The diameters $d_{g}$ (the blue squares are $r_{g}$ ) in the CF3 fractograms span roughly from $40 \mathrm{~nm}$ to $1000 \mathrm{~nm}$, with average sizes (computed from the $r_{g}$ at the UV peak maximum) equal to $\mathrm{d}_{\mathrm{g}} \approx 260 \mathrm{~nm}$ (plot a - Zano10) and $\mathrm{d}_{\mathrm{g}} \approx 200 \mathrm{~nm}$ (plot c-Zano10 Plus), respectively. It is worthwhile to observe that the range of the particles dimensions are referred to the UV profile; $r_{g}$ values larger than $500 \mathrm{~nm}$ (MALS) are here reported and commented to underline that the sample contain very large aggregates. It must be recalled, in fact, that MALS sizes are based on the Rayleigh-Debye-Gans (RDG) approximation [33-35], which sets as rough limits for $r_{g}$ at $10 \mathrm{~nm}$ and $500 \mathrm{~nm}$, respectively as lowest and largest reliable size.As far as it concerns the AF4 separations, the measured diame-

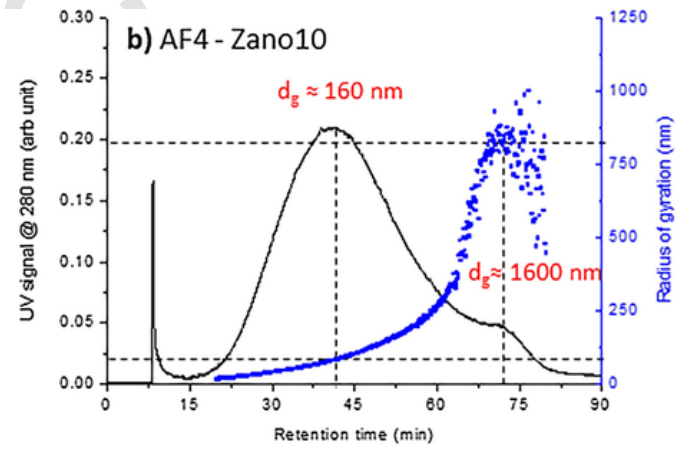


ters are in the range of $20-1800 \mathrm{~nm}$ (plot b), with an average size of $160 \mathrm{~nm}$ at the UV-peak maximum, while the coated particles (plot d) have diameters in the range of 90-1300 nm, with a prominent size of $120 \mathrm{~nm}$. The second population includes very large particles/aggregates, with diameters between $500 \mathrm{~nm}$ up to $1300 \mathrm{~nm}$.

The comparison between the two separation techniques highlights how they can give complementary information because of their different separation potentialities. AF4 is able to separate particles of very small sizes better than CF3 since the separation is based on their hydrodynamic properties and not on the mass. By a rough calculation based on sedimentation FFF theory [36], a $30 \mathrm{~nm}$ spherical particle would have a retention time of 4 min under the selected CF3 separation conditions. On the other hand, because of its lower separation power, AF4 is able to include also larger aggregates in the fractogram, which CF3 would only separate with an extremely high retention time (secondary population).

Another important aspect, which has to be underlined is the role of the detection. The main peak of the coated particles is narrower and it elutes approximately $10 \mathrm{~min}$ earlier than that of the uncoated particles (42 min - plot b). If the AF4 separation would have been monitored only by UV-vis a plausible hypothesis explaining the time shift could be that the triethoxycaprylyl silane coating causes a repulsion between the particles and the accumulation wall, determining an equilibrium position of the coated particles (plot d) farther away from the accumulation wall than what observed for the uncoated particles (plot b). The on-line MALS detection proves instead, in an independent manner, that the triethoxy caprylylsilane coating limits the particle aggregation when the particles are dispersed in $0.5 \% \mathrm{NC}$ solution, since the dimensions, determined in correspondence to the peak maximum are $120 \mathrm{~nm}$ (d) vs $160 \mathrm{~nm}$ (b), and the secondary peak maxima differ significantly, $\mathrm{d}_{\mathrm{g}} \approx 1260 \mathrm{~nm}$ (d) vs $1600 \mathrm{~nm}$ (b).

A further additional check about the average sizes of the $\mathrm{ZnO}$ particles measured by AF4 was done through on-line coupling with DLS (Fig. 2). The normalized fractograms for the sample Zano10 shows a narrow single peak (plot a) with an average size hydrodynamic diameter $\mathrm{d}_{\mathrm{h}} \approx 140 \mathrm{~nm} / 150 \mathrm{~nm}$ (referred to the DLS and UV profiles, respectively) and a size range spanning from $d_{h}=20 \mathrm{~nm}$ to $\mathrm{d}_{\mathrm{h}}=400 \mathrm{~nm}$. The sample Zano10 Plus (plot b) shows a bimodal distribution confirming the UV profile. The average size of the main population is $d_{h} \approx 140 \mathrm{~nm}$. Fig. 2 also reports the sizes determined by MALS (blue squares) for a direct comparison; $r_{h}$ and $r_{g}$ data start to disagree after 50 and 45 min of elution, respectively. Fig. S-6 reports the $r_{g} / r_{h}$ trends for both samples as a function of the retention time; values span from $0.6(20 \mathrm{~min})$ up to $2.0(80 \mathrm{~min})$, with values of 0.9 and 0.85 at the respective peak maxima, strongly indicating an irregular shape of the particles and aggregates [37].

From an instrumental point of view, when possible, the application of different detectors on-line (UV-vis, MALS and/or DLS) guarantees the undisputed advantage of collecting size information independently of the retention time data, which might be affected by physico-chemical interactions difficult to reproduce during the channel calibration done with standards [38-40].

The high dimensional heterogeneity highlighted by both FFF techniques is supported by the SEM observations, whose results are exemplified by the pictures reported in Fig. 3. Both Zano10 and Zano10 Plus particles have an irregular shape; they are aggregated and agglomerated and a general glance shows that there are no important differences between the two $\mathrm{ZnO}$ particle types. The dimensions of the primary particles are $<100 \mathrm{~nm}$; some of them were measured and the values are marked on the pictures; they were $66 \mathrm{~nm}$ and $85 \mathrm{~nm}$ for the Zano10 (picture b) and $31 \mathrm{~nm}$ and $47 \mathrm{~nm}$ and Zano10 Plus (picture d), respectively. The absence of smaller particles is not excluded since the membrane had pores of $100 \mathrm{~nm}$.

\subsection{Dimensional characterization of the $\mathrm{ZnO}$ particles extracted from the sample formulations}

The most critical step in the size characterization of insoluble, inorganic particles, used to formulate cosmetic products, is their extraction from the complex matrix, in other words, the sample preparation. In order to isolate this type of analyte, it is often indispensable to chemically destroy the complex matrix, a procedure that might introduce important artefacts altering the original particle sizes or the original particle size distributions [41].

Cosmetic formulations can be distinguished in water-in-oil $\mathrm{W} / \mathrm{O}$ and oil-in-water $\mathrm{O} / \mathrm{W}$ emulsions, as the $\mathrm{ZnO}$ particles available on the market exhibit either an uncoated, polar, surface or a surface modified with molecules to make them lipophilic and suitable for less polar matrices.

Since one of the final aims of this study is the analysis of $\mathrm{ZnO}$ particles dispersed in commercial baby care cosmetic emulsions, where they might be incorporated up to $25 \% \mathrm{wt}$ [8], the uncoated and coated $\mathrm{ZnO}$ particles were included both in oil-in-water emulsions $(\mathrm{F} 1 \mathrm{O} /$ $\mathrm{W})$ and $\mathrm{F} 3(\mathrm{O} / \mathrm{W})$ ), and in water-in-oil emulsions $(\mathrm{F} 2(\mathrm{~W} / \mathrm{O})$ and $\mathrm{F} 4$ $(\mathrm{W} / \mathrm{O}))$. These four creams formulated in-house were then processed according to different protocols to determine the most suit-

\section{a) AF4 - Zano10}

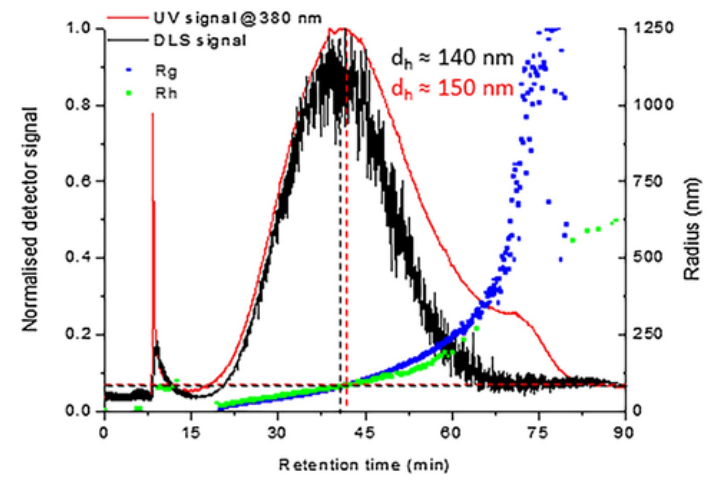

\section{b) AF4 - Zano10 Plus}

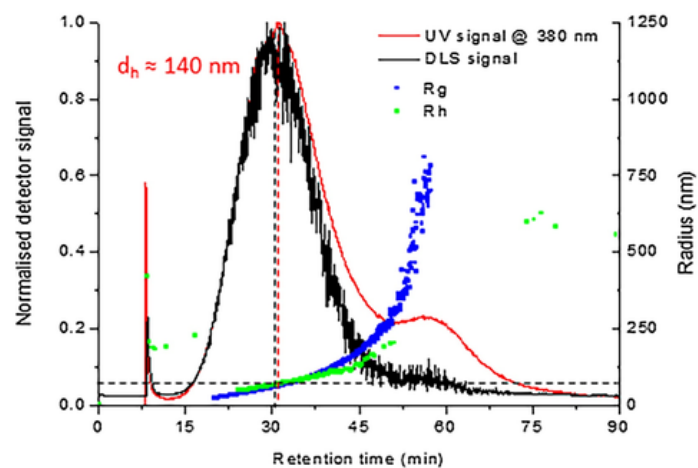

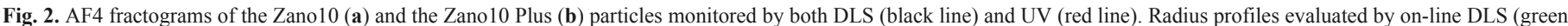

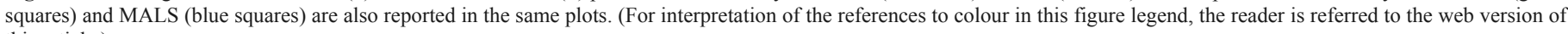
this article.) 

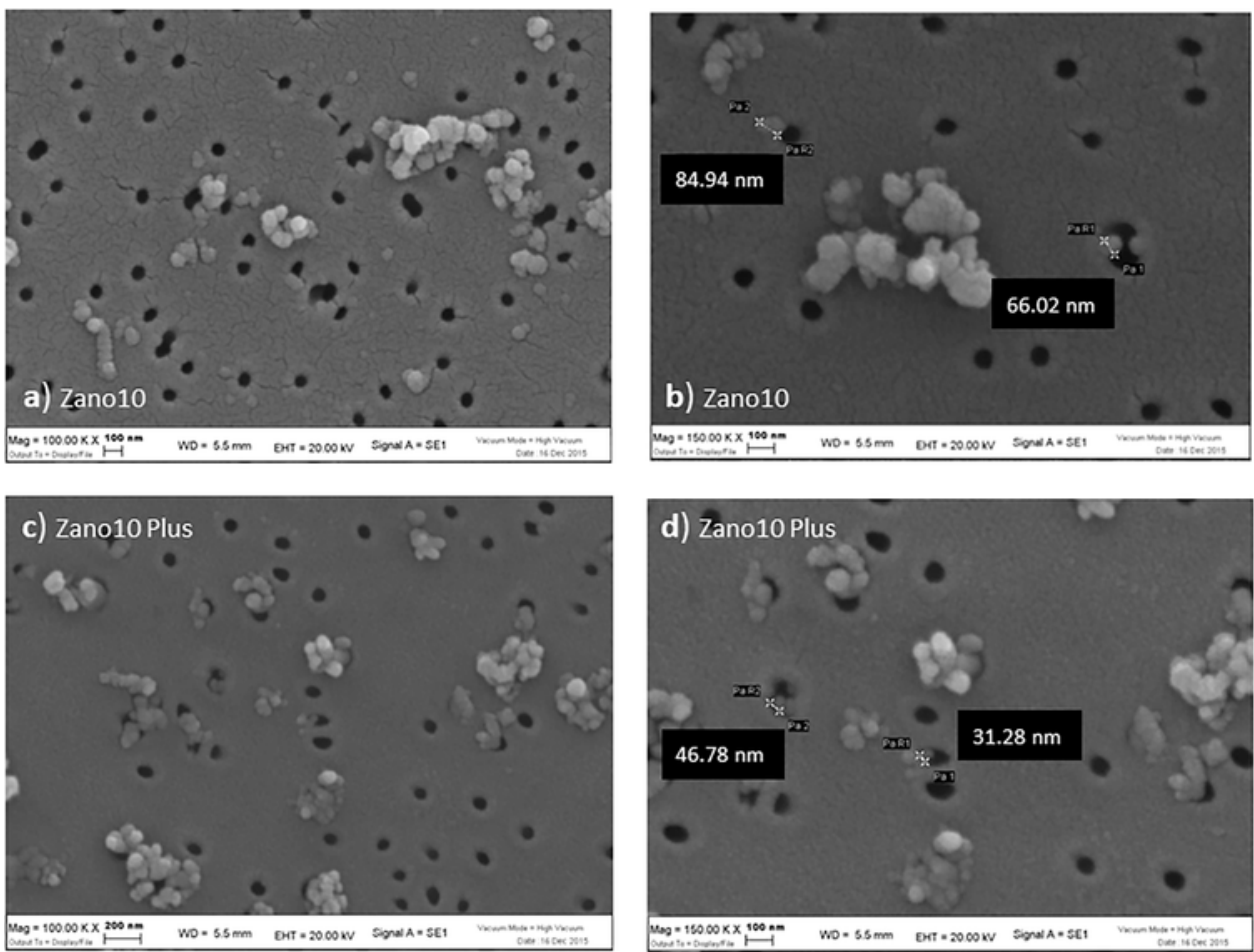

Fig. 3. SEM pictures of the Zano10 sample (plot a-b) and Zano10 Plus sample (plots c-d). Magnification $100 \mathrm{k}(\mathrm{a}, \mathrm{c})$ and $150 \mathrm{k}(\mathbf{b}, \mathbf{d})$

able extraction procedures that do not alter the original $\mathrm{ZnO}$ particle size distribution. The selection of the extraction method, which depended on the respective emulsion type and on $\mathrm{ZnO}$ particles, was also connected with the analysis procedure, since only those FFF analyses that generated reproducible and repeatable fractograms were considered. The samples analysed by CF3 and AF4 are listed in Table 1.

\subsubsection{Dimensional characterization of the Zano10 particles extracted from the $\mathrm{O} / \mathrm{W}$ emulsion}

The $\mathrm{O} / \mathrm{W}$ emulsion was dispersed in deionised water and the resulting dispersion was either treated with $n$-hexane (method A) or the emulsion was directly treated with a $2: 1 \mathrm{v} / \mathrm{v}$ mixture of ethanol/ $\mathrm{n}$-hexane solution (method $\mathrm{B}$ ). In both cases, the $\mathrm{ZnO}$ particles, separated by centrifugation, were re-suspended in a $0.5 \% \mathrm{v} / \mathrm{v}$ NC solution. Fig. 4 reports the $\mathrm{CF} 3$ fractograms along with the sizes determined by MALS. Plots (a) and (b) refer to the particles extracted according to the methods A and B, respectively. Fractogram (a) displays a very high void time signal (dashed red rectangle) compared to the main peak, probably due to sample components not properly fractionated. The particle sizes, corresponding to the peak, span between $d_{g}=90 \mathrm{~nm}$ up to roughly $d_{g}=1300 \mathrm{~nm}$, with an average size of $260 \mathrm{~nm}$ (maximum) perfectly in line with the sizes of Fig. 1a. The separation of the same extract by AF4 (Fig. S-7a) produced a tailed peak; the particle size range $\left(\mathrm{d}_{\mathrm{g}}=60 \mathrm{~nm}-800 \mathrm{~nm}\right)$ was confirmed, but the average dimension of $250 \mathrm{~nm}$ (referred to the maximum of the UV profile) was significantly higher than, that determined for the original powder (Fig. 1b).

The particles extracted according to method B produced reproducible peaks in term of shape (Fig. 4b), but the CF3 channel required a couple of injection in order to obtain a stable detector signal (saturation of the accumulation wall). The sizes linearly increased between $d_{\mathrm{g}}=35 \mathrm{~nm}$ to $d_{\mathrm{g}}=1200 \mathrm{~nm}($ at $\approx 100 \mathrm{~min})$, with $390 \mathrm{~nm}$ at the
UV-peak maximum, which is in disagreement with the sizes determined for the original powder (Fig. 1a).

3.3.2. Dimensional characterization of the Zano10 particles extracted from the $W / O$ emulsion

The uncoated $\mathrm{ZnO}$ particles were extracted from the $\mathrm{W} / \mathrm{O}$ emulsion according to the methods $\mathrm{C}$ ( $n$-hexane) and D (a mixture $2: 1 \mathrm{v} / \mathrm{v}$ ethanol/n-hexane). After treatment with $n$-hexane, the suspension appeared dense and very concentrated; with particles adhereding onto the vial glass surface, from which they could be only detached by adding deionised water. The suspension was very unstable and prone to flocculate quite rapidly. To obtain a stable suspension, the particles were re-dispersed in $0.5 \% \mathrm{NC}$ and sonicated for $45 \mathrm{~min}$. Fig. 4c shows an example of a CF3 fractogram, in which the sizes range from approximately $\mathrm{d}_{\mathrm{g}}=40 \mathrm{~nm}$ to $760 \mathrm{~nm}$, with an average dimension (UV-peak maximum) of roughly $300 \mathrm{~nm}$. On the other hand, the AF4 fractionation produced an incorrect separation, described by a fronted peak, which was very high and narrow compared to the initial distribution with sizes, derived from the MALS signal, unusually oscillating (Fig. S-7b)

Likewise, method D produced a suspension difficult to be fractionated, as proven by the CF3 fractogram shown in Fig. 4d. Large parts of the sample eluted in the void peak (dashed red rectangle) while the rest formed a broad peak, located at very high retention times. The sizes determined by MALS ranged between $\mathrm{d}_{\mathrm{g}}=30 \mathrm{~nm}$ and $2000 \mathrm{~nm}$, with an average value of $700 \mathrm{~nm}$ at the UV-peak maximum. The analysis of this sample by AF4 was impossible as, no sample elution was registered, confirming the inappropriateness of the AF4 technique to analyse such a suspension type.

\subsubsection{Dimensional characterization of the Zano10 plus particles extracted from the $\mathrm{O} / \mathrm{W}$ emulsion}

The $\mathrm{ZnO}$ particles coated with triethoxycaprylyl silane were extracted from the $\mathrm{O} / \mathrm{W}$ emulsion with the methods $\mathrm{A}$ and $\mathrm{B}$. The sus- 

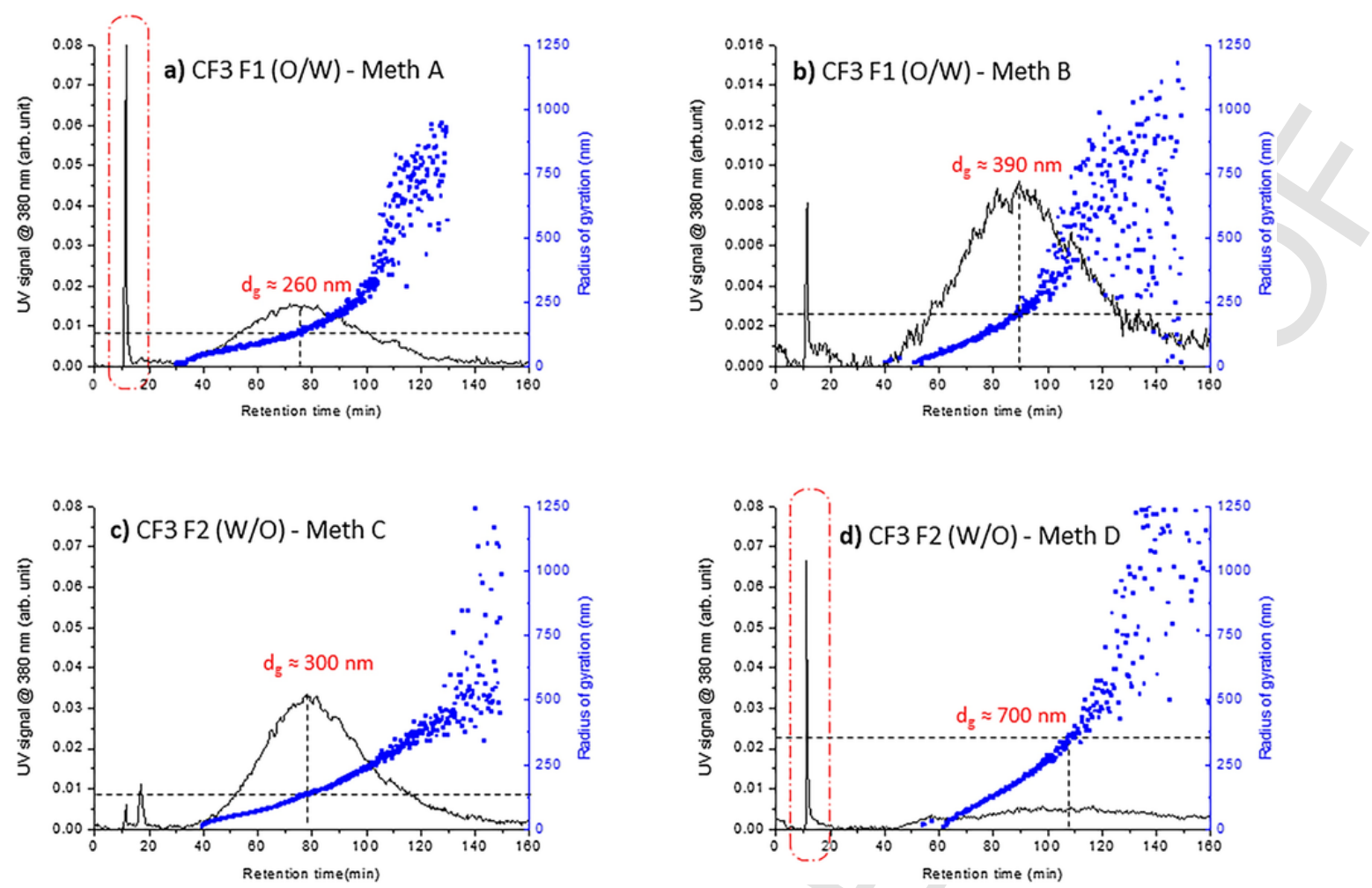

Fig. 4. CF3 fractograms of the Zano10 particles extracted from the O/W emulsion according to method A (plot a) and method B (plot $\mathbf{b}$ ). The plots $\mathbf{c}$ and $\mathbf{d}$ are the fractograms of the Zano 10 particles extracted from the $\mathrm{W} / \mathrm{O}$ emulsion according to method $\mathrm{C}$ and method $\mathrm{D}$, respectively.

pension obtained from method A produced a CF3 fractogram (Fig. 5a) showing a single, symmetric peak with an average particle size $d_{g}$ of $180 \mathrm{~nm}$ at the UV-peak maximum, close to the size measured in the original powder $\left(\mathrm{d}_{\mathrm{g}} \approx 200 \mathrm{~nm}-\right.$ Fig. $\left.1 \mathrm{c}\right)$. The separation occurred linearly and the dimensions of the aggregates/agglomerates exiting after 120 min increased quite rapidly to roughly $\mathrm{d}_{\mathrm{g}} \approx 1760 \mathrm{~nm}$. The AF4 analysis of the same suspension allowed the separation of the largest aggregates/agglomerates as well. The graph (Fig. S-10a) shows a bimodal elution profile, whose average sizes, measured at the respective peak maxima of the $92^{\circ}$ MALS signal, were bigger than those determined from the analysis of the original powder $\left(\mathrm{d}_{\mathrm{g}} \approx 140 \mathrm{~nm}\right.$ vs $\mathrm{d}_{\mathrm{g}} \approx 120 \mathrm{~nm}$, and $\mathrm{d}_{\mathrm{g}} \approx 1000 \mathrm{~nm}$ vs $\mathrm{d}_{\mathrm{g}} \approx 750 \mathrm{~nm}-$ Fig. $\left.1 \mathrm{~d}\right)$. The same fractionation was also monitored by DLS (Fig. S-10c). The graph shows a single peak and the hydrodynamic diameter measured in correspondence with the intensity maximum, was $\mathrm{d}_{\mathrm{h}} \approx 160 \mathrm{~nm}$, proving that the detector plays an important role in describing the same fractionation.

The CF3 and AF4 analysis of the suspension obtained from the extraction method $\mathrm{B}$ resulted in a bimodal elution profile for both techniques. The whole range of $r_{g}$ values determined by MALS during the $\mathrm{CF} 3$ fractionation is equivalent to that reported in Fig. 1 $\mathbf{c}$ but the average size of $350 \mathrm{~nm}$ at the first UV-peak maximum is in disagreement with the $200 \mathrm{~nm}$ measured for the original powder and the UV profiles differ in correspondence of the second population. On the contrary, the AF4 fractionation (Fig. S-10b) produced a bimodal size distribution in line with that of the original powder (Fig. 1d), but it differs for the average size of the second population $\left(\mathrm{d}_{\mathrm{g}} \approx 700 \mathrm{~nm} \mathrm{vs} \mathrm{d}_{\mathrm{g}} \approx 1260 \mathrm{~nm}\right)$.

\subsubsection{Dimensional characterization of the Zano10 plus particles extracted from the $\mathrm{W} / \mathrm{O}$ emulsion}

In analogy to the uncoated particles, the extraction of the Zano10 Plus particles from the $\mathrm{W} / \mathrm{O}$ emulsions was done by applying the methods $\mathrm{C}$ and $\mathrm{D}$. The $\mathrm{CF} 3$ separation of the particles extracted with method $\mathrm{C}$ produced a broad peak (Fig. 5c), exiting the channel a high retention time. The size determined by MALS confirmed the presence of very large aggregates/agglomerates, whose average diameters were roughly $\mathrm{d}_{\mathrm{g}} \cong 1200 \mathrm{~nm}$. The AF4 separation instead gave irreproducible results (data not shown).

The $\mathrm{ZnO}$ coated particles extracted through the method $\mathrm{D}$ generated a fractogram (Fig. 5d), whose signal UV was very weak and shifted at higher retention times when compared to that obtained with the original powder (Fig. 1c); the average size at the UV-peak maximum was of $440 \mathrm{~nm}(+120 \%)$. The same suspension, analysed by AF4 (Fig. S-10d), produced a fractogram, with a bimodal elution profile in good correlation with the original powder, but the average sizes measured in correspondence with the first population were much higher $\left(\mathrm{d}_{\mathrm{g}}=220 \mathrm{~nm}\right.$ vs $\mathrm{d}_{\mathrm{g}}=120 \mathrm{~nm}$, Fig. 1d $)$.

A summary of the minimum, maximum and average sizes determined by MALS from the CF3 and AF4 fractionations is reported in Table 3.

The conclusions, which can be drawn from this careful examination are that extraction methods $\mathrm{A}$ are the methods of choice when uncoated and coated $\mathrm{ZnO}$ particles are included in oil-in-water emulsions; while in case of a water-in-oil emulsion, method $\mathrm{C}$ is advisable if the $\mathrm{ZnO}$ particles are uncoated, method $\mathrm{D}$ if the particles are superficially modified (Fig. S-11). However, these latter two extraction methods could produce aggregates/agglomerates of larger sizes. As far as it concerns the technique, CF3 revealed to be the most robust, since it allowed the fractionation of all types of suspensions. AF4 

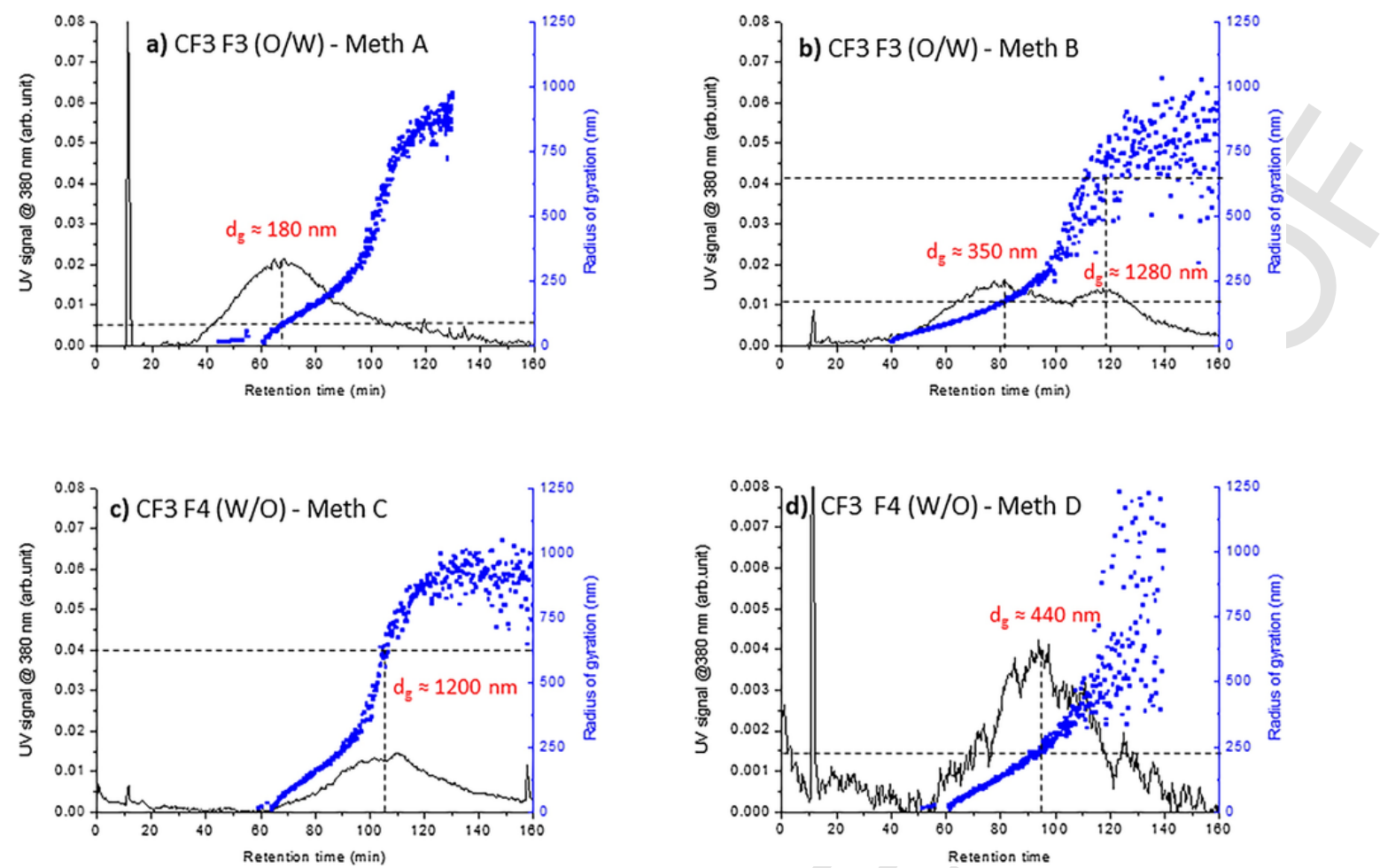

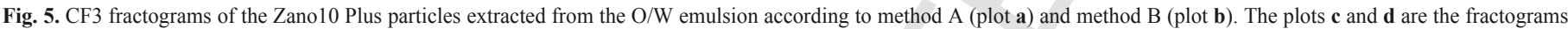
of the Zano 10 Plus particles extracted from the W/O emulsion according to method $\mathrm{C}$ and method $\mathrm{D}$, respectively.

may also deliver promising results, however further systematic studies with membranes of different chemical compositions need to be performed for the different types of suspensions. These conclusions are the starting point for the analysis of the commercial products.

\subsection{Dimensional characterization of particles inside commercial cosmetic formulations}

The commercial products were cosmetic formulations for the baby bottom skin care. $\mathrm{ZnO}$ is usually present in these topical creams or ointments at different concentration levels, to a maximum of $40 \% \mathrm{wt}$ (highest percentages of $\mathrm{ZnO}$ are possible in galenic formulations, i.e. formulated following a medical prescription). These products are specially designed to prevent any diaper rash, redness and irritation; zinc oxide forms a protective but breathable barrier, that keeps the nappy area dry.

The careful reading of the ingredients list reported on the packages (Supp. Mat. § S-2) allowed to recognize the emulsion type and to apply the appropriate extraction procedure, aware that no information was available about the surface of the $\mathrm{ZnO}$ particles (presence of a surface coating).

After a preliminary test aiming to evaluate the solubility of the emulsions in $n$-hexane, samples CS- 1 and CS-2 were treated according to method D since they appeared as $\mathrm{W} / \mathrm{O}$ emulsions, and sample CS-3 with method A since it looked like an $\mathrm{O} / \mathrm{W}$ emulsion. The extracted particles were all re-dispersed in a $0.5 \% \mathrm{NC}$ solution and analysed by $\mathrm{CF} 3$ using a $0.2 \% \mathrm{NC}$ solution as mobile phase.

All fractograms (Fig. 6a-c), well reproducible, present a single, broad peak, with a minimum dimension differing from sample to sample, but with a common maximum size close to $2 \mu \mathrm{m}$. The size ranges of the particles/aggregates/agglomerates measured by MALS show interesting differences. CS-1 contains particles of small dimensions $\left(\mathrm{d}_{\mathrm{g}} \cong 20 \mathrm{~nm}\right)$ (Fig. 6a), while the CS-2 and CS-3 samples apparently do not contain particles (aggregates) $<100 \mathrm{~nm}$, as confirmed by the SEM pictures, and the sizes of their particles span between 270 and $800 \mathrm{~nm}$, and $160-1750 \mathrm{~nm}$, with average sizes of $420 \mathrm{~nm}$ and $300 \mathrm{~nm} \mathrm{~nm}$ at the respective UV-peak maxima (Fig. 6b,c).

CS-1 appeared as the most concentrated and polydispersed formulation since the fractionation was still unfinished after $200 \mathrm{~min}$. The average dimension is $\mathrm{d}_{\mathrm{g}} \cong 400 \mathrm{~nm}$ and the presence of single $\mathrm{ZnO}$ particles $<100 \mathrm{~nm}$ was confirmed by the SEM observation. If this would be a study aiming at the safety assessment of this products, its median diameter D50 and the D1 of the particle number size distribution should be evaluated to verify if they are $>30 \mathrm{~nm}$ and $>20 \mathrm{~nm}$ respectively, as recommended in the opinion SCCS/1489/12 [7].

\subsection{Preliminary quantitative evaluations}

All data presented and discussed in the previous paragraphs lack of quantitative considerations. This aspect, essential to set up validated methods of analysis [42-44], was not neglected but limited to the aims of this study. Nevertheless, the present investigation allows listing the steps that must be kept under control.

Firstly, it is necessary to experimentally verify the actual content of $\mathrm{ZnO}$ in all samples, also when the concentration is declared. The batch ICP-OES analysis of all samples, after their acidic mineralization, showed interesting discrepancies in either the Zano powders and the in-house formulated creams.

The $\mathrm{ZnO}$ content of the Zano powders compared to the amount of $\mathrm{ZnO}$ declared by the producers was $(95.9 \pm 1.1) \% \mathrm{wt}($ Zano10) and $(95.1 \pm 0.6) \%$ wt (Zano10 Plus) (Table 4) against the declared purities of $99 \mathrm{wt} \%$ and $96 \%$ wt. The missing $4 \%$ wt in Zano10 Plus accounts for the coating. 
Table 3

Summary of the principal dimensions of the fractionated samples determined by MALS.

\begin{tabular}{|c|c|c|c|c|c|}
\hline $\begin{array}{l}\text { Sample } \\
\text { name }\end{array}$ & Technique & $\begin{array}{l}\text { Average peak } \\
\max _{\mathrm{g}}(\mathrm{nm})\end{array}$ & $\begin{array}{l}\text { Average } \\
\text { minimum size } \\
d_{g}(n m)\end{array}$ & $\begin{array}{l}\text { Average } \\
\text { maximum size } \\
d_{g}(n m)\end{array}$ & Figure \\
\hline $\begin{array}{l}\text { Zano10 - } \\
\text { powder }\end{array}$ & CF3 & 260 & 40 & 1100 & 1a \\
\hline $\begin{array}{l}\text { Zano10 - } \\
\text { powder }\end{array}$ & AF4 & $160-1600$ & 40 & 1600 & $1 b$ \\
\hline $\begin{array}{l}\text { Zano Plus } 10 \\
\text { - powder }\end{array}$ & CF3 & 200 & 40 & 1250 & $1 \mathrm{c}$ \\
\hline $\begin{array}{l}\text { Zano Plus } 10 \\
\text { - powder }\end{array}$ & AF4 & $120-1260$ & 50 & 1260 & $1 d$ \\
\hline $\begin{array}{l}\mathrm{F} 1(\mathrm{O} / \mathrm{W})- \\
\mathrm{A}(\text { Zano } \\
10)\end{array}$ & CF3 & 260 & 90 & 1300 & $4 a$ \\
\hline $\begin{array}{l}\mathrm{F} 1(\mathrm{O} / \mathrm{W})- \\
\text { A (Zano } \\
10)\end{array}$ & AF4 & 250 & 60 & 900 & S-7a \\
\hline $\begin{array}{l}\mathrm{F} 1(\mathrm{O} / \mathrm{W})- \\
\mathrm{B}(\text { Zano } 10)\end{array}$ & CF3 & 390 & 35 & 1200 & $4 b$ \\
\hline $\begin{array}{l}\mathrm{F} 2(\mathrm{~W} / \mathrm{O})- \\
\mathrm{C}(\text { Zano } 10)\end{array}$ & CF3 & 300 & 40 & 760 & $4 c$ \\
\hline $\begin{array}{l}\mathrm{F} 2(\mathrm{~W} / \mathrm{O})- \\
\mathrm{C}(\text { Zano } 10)\end{array}$ & AF4 & 500 & 110 & 1000 & $S-7 b$ \\
\hline $\begin{array}{l}\mathrm{F} 2(\mathrm{~W} / \mathrm{O})- \\
\mathrm{D}(\text { Zano } \\
10)\end{array}$ & CF3 & 700 & 30 & 2000 & $4 d$ \\
\hline $\begin{array}{l}\mathrm{F} 3(\mathrm{O} / \mathrm{W})- \\
\text { A (Zano } 10 \\
\text { Plus) }\end{array}$ & CF3 & 180 & 35 & 1760 & $5 \mathrm{a}$ \\
\hline $\begin{array}{l}\mathrm{F} 3(\mathrm{O} / \mathrm{W})- \\
\text { A (Zano } 10 \\
\text { Plus) }\end{array}$ & AF4 & $140-1000$ & 50 & 1100 & S-10a \\
\hline $\begin{array}{l}\mathrm{F} 3(\mathrm{O} / \mathrm{W})- \\
\mathrm{B} \text { (Zano } 10 \\
\text { Plus) }\end{array}$ & CF3 & $350-1280$ & 40 & 1600 & $5 b$ \\
\hline $\begin{array}{l}\mathrm{F} 3(\mathrm{O} / \mathrm{W})- \\
\mathrm{B}(\text { Zano } 10 \\
\text { Plus) }\end{array}$ & AF4 & $130-700$ & 40 & 1000 & S-10b \\
\hline $\begin{array}{l}\mathrm{F} 4(\mathrm{~W} / \mathrm{O})- \\
\mathrm{C} \text { (Zano } 10 \\
\text { Plus) }\end{array}$ & CF3 & 1200 & 40 & 1900 & $5 c$ \\
\hline $\begin{array}{l}\mathrm{F} 4(\mathrm{~W} / \mathrm{O})- \\
\mathrm{D} \text { (Zano } 10 \\
\text { Plus) }\end{array}$ & CF3 & 440 & 50 & 1360 & $5 \mathrm{~d}$ \\
\hline $\begin{array}{l}\mathrm{F} 4(\mathrm{~W} / \mathrm{O})- \\
\mathrm{D} \text { (Zano } 10 \\
\text { Plus) }\end{array}$ & AF4 & $220-750$ & 80 & 1400 & S-10d \\
\hline CS-1 & CF3 & 400 & 35 & 1800 & $6 a$ \\
\hline $\mathrm{CS}-2$ & CF3 & 500 & 270 & 1500 & $6 b$ \\
\hline $\mathrm{CS}-3$ & CF3 & 350 & 160 & 1750 & $6 c$ \\
\hline
\end{tabular}

The four in-house emulsions, prepared as sample tests were formulated by nominally adding $20 \%$ wt of $\mathrm{ZnO}$ powder. The applied protocol foresees the addition of the $\mathrm{ZnO}$ as final ingredient, independently of the $\mathrm{ZnO}$ type, in order to incorporate the $\mathrm{ZnO}$ in the external phase, water or oil, depending on the emulsion type. Because of this procedure, the $\mathrm{ZnO}$ content (Table 4 ), was roughly $26.5 \% \mathrm{wt}$ $\mathrm{F} 1(\mathrm{O} / \mathrm{W}), 17 \%$ wt F2 (W/O), 18\% wt F3 (O/W) and 28.5\% wt for the F4 (W/O). The large discrepancy from the nominal value could be probably ascribed to the final homogenisation step, which would deserve an optimization study establishing the right time to get a homogeneous product for each formulation as it normally occurs in industrial processes. An alternative preparation method might be adopted from the common formulation of sunscreen creams, in which the oil phase containing lipophilic substances and the aqueous phase containing hydrophilic substances are separately heated in a water bath; then gradually mixed under constant stirring until the mixture is congealed at room temperature. The $\mathrm{ZnO}$ particles would be dispersed in the oil or aqueous phase, depending on their surface coating [45]. This method usually allows a more effective mixing/dispersion of the inorganic particles [46]. The inhomogeneous distribution of the $\mathrm{ZnO}$ in the in-house creams was not considered, however, a limit for setting up the extraction method, since the observed correspondence between the initial and final (after the extraction) particle sizes was an indirect proof of a good representative particle sampling.

The ICP-OES and ICP-MS analyses of the mineralised commercial products (topical dermatological formulations, in which the $\mathrm{ZnO}$ concentration can reach the $40 \% \mathrm{wt}$ ) produced data with very low standard deviations (Table 5), a confirmation that the industrial preparations are homogeneous. Sample CS-3 contained 5\% wt of $\mathrm{ZnO}$, while the CS-2 and CS-1 samples contained $17 \%$ wt and $19.6 \%$ wt $(20 \% \mathrm{wt}$ declared on the label), values in line with those of the in-house formulated samples. Small discrepancies in the declared concentrations of the commercial products were also found by C.Cascio et al. [47] in the case of silver NPs analysis.

Secondly, it is relevant to determine the extraction yields and to know the concentration of the suspensions that have to be injected in the FFF channels. This latter aspect was faced by analysing the extracted suspensions directly by ICP-MS. Unfortunately, the data were not reproducible, likely because the suspensions still contained traces of the organic solvent. An acidic mineralisation of these suspensions is probably the solution, but a study aiming to define the chemical composition of the mineralisation acidic solution is necessary to ensure a complete decomposition of organic solvent residuals. As far as it concerns the extraction yields, there are several steps, in which sample loss might occur including, e.g. adhesion of the creams on the glass vial walls or incidental aspiration of the aqueous phase during the organic phase removal (with the Pasteur pipette) after the centrifugation.

Lastly, it is very important to evaluate the CF3 (or AF4) separation yields, since low recoveries are possible, especially with the AF4 technique [48]. This evaluation is possible by coupling the FFF channels with a specific element detector, such as the ICP-MS, which is able to monitor on-line the amount of $\mathrm{Zn}$ fractionated. The FFF-ICP-MS coupling obviously increases the analysis costs, justified only when the separation set up is completed, i.e. after being sure of having chosen the right technique for the purposes of the research, after having established the proper separation parameters (flow rates, field strength, decay profile, etc.) and after having tested the reproducibility and the repeatability of the separations.

\section{Conclusions}

The results obtained in this study confirmed that the stability of the $\mathrm{ZnO}$ particles, uncoated or superficially modified, depends on the $\mathrm{pH}$, the ionic strength, the chemical composition and the presence of surfactant in the suspending medium. Measuring the $\zeta$-potential of the suspensions gave a good indication of the reached stability conditions. The most stable suspensions were obtained by dispersing the powders in $0.5 \% \mathrm{v} / \mathrm{v} \mathrm{NC}$ solution and sonicating them for $60 \mathrm{~min}$ in an ice-cooled ultrasonic bath.

There are no "one extraction method fits all" solutions. They need to be tailored toward the emulsion (W/O and $\mathrm{O} / \mathrm{W}$ ) and the type of particles, taking into account the hydrophilic or lipophilic surface. Unfortunately, when commercial products are analysed, the secrecy 

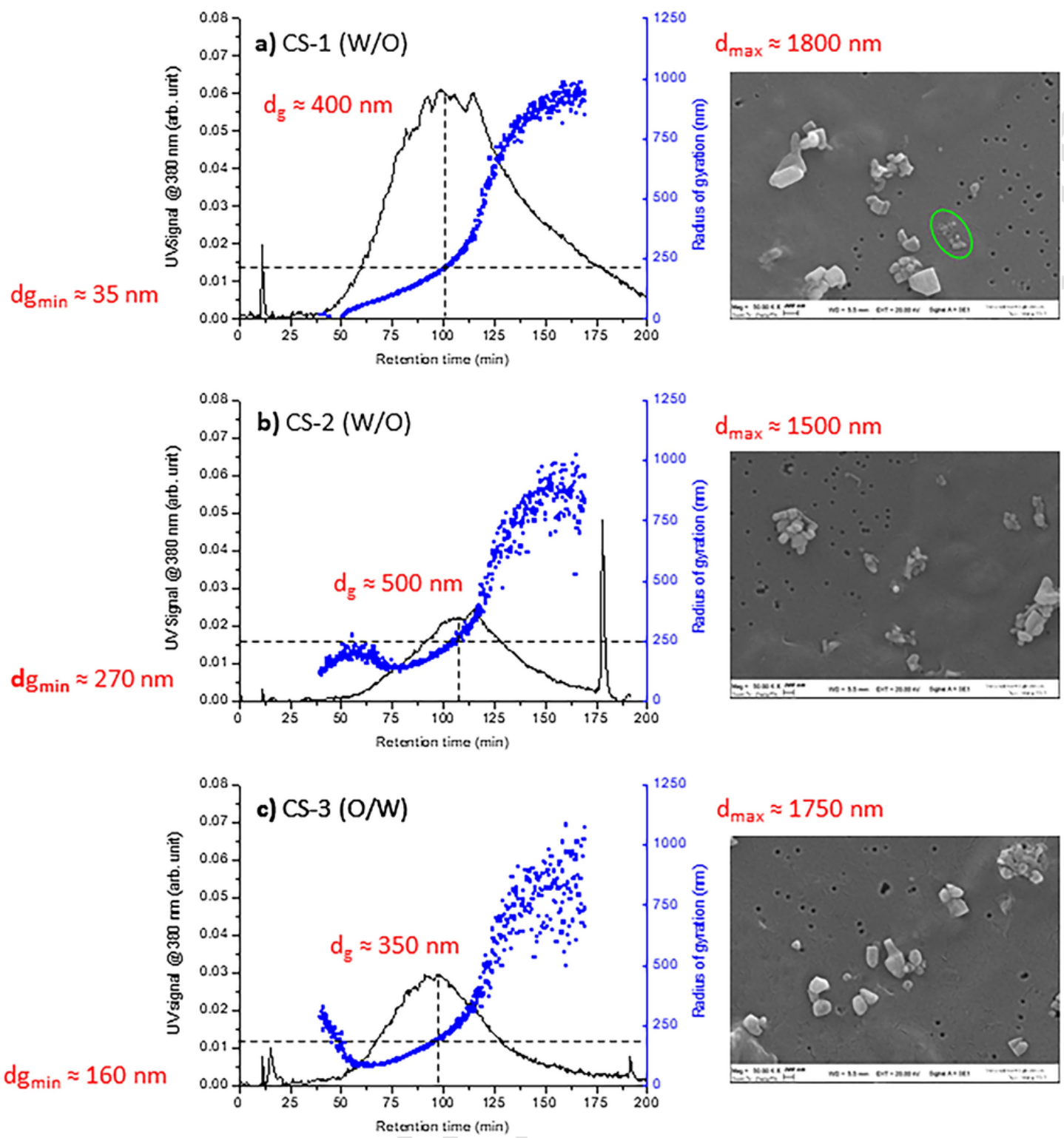

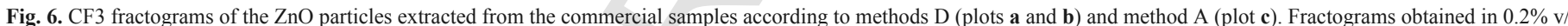
$\mathrm{v}$ NC. All SEM pictures have been acquired at $50 \mathrm{k}$ magnification, EHT of $20 \mathrm{kV}$ and a WD of $5.5 \mathrm{~mm}$.

Table 4

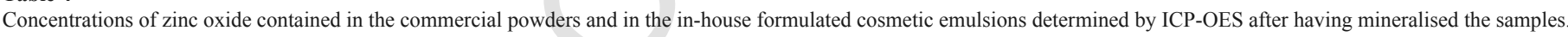
Analyses were performed in triplicate.

\begin{tabular}{|c|c|c|c|c|c|c|}
\hline Sample & \multicolumn{3}{|l|}{ Zano10 } & \multicolumn{3}{|c|}{ Zano10 Plus } \\
\hline & \multicolumn{3}{|c|}{$(\% \mathrm{wt} \pm \mathrm{RSD} \%)$} & \multicolumn{3}{|c|}{$(\% \mathrm{wt} \pm \mathrm{RSD} \%)$} \\
\hline $\begin{array}{l}\mathrm{ZnO} \\
(\lambda=213.857 \mathrm{~nm})\end{array}$ & $95.9 \pm 1$. & $26.7 \pm 5.8$ & $16.9 \pm 1.3$ & $95.1 \pm 0.6$ & $18.0 \pm 2.9$ & $28.6 \pm 3.6$ \\
\hline $\begin{array}{l}\mathrm{ZnO} \\
(\lambda=202.548 \mathrm{~nm})\end{array}$ & $95.3 \pm 1.2$ & $26.4 \pm 5.7$ & $16.7 \pm 1.3$ & $94.6 \pm 0.4$ & $17.8 \pm 2.9$ & $28.3 \pm 3.6$ \\
\hline
\end{tabular}

of the formulation recipe does not allow having the certainty of determining a particle size distribution, which corresponds to the original $\mathrm{ZnO}$ powdered ingredient. However, depending on the analysis purposes, this might not be a detrimental aspect, since the aim could sim- ply be the determination of the aggregation/agglomeration state of the $\mathrm{ZnO}$ particles in the final product, as it is spread out onto the skin.

Concerning the two FFF techniques, CF3 and AF4 were compared in this study. CF3 was able to sort all types of suspensions, with 
Table 5

Zinc oxide concentration determined by ICP-OES and ICP-MS.

\begin{tabular}{llll}
\hline & \multicolumn{1}{l}{$\begin{array}{l}\text { CS-1 (W/O) (nominal conc } \\
\text { 20\%) }\end{array}$} & CS-2 (W/O) & CS-3 (O/W) \\
\hline $\begin{array}{lll}\mathrm{ZnO} \% \text { wt (ICP- } \\
\text { OES) }\end{array}$ & $19.54 \pm 0.09$ & $17.18 \pm 0.25$ & $4.88 \pm 0.02$ \\
$\mathrm{ZnO} \%$ wt (ICP-MS) & $19.76 \pm 0.20$ & $16.69 \pm 0.48$ & $5.43 \pm 0.12$ \\
\hline
\end{tabular}

ICP-OES data; readings done at $\lambda=213.857 \mathrm{~nm}$; calibration curve: $\mathrm{y}=274587.9 \mathrm{x}-4700.8 \mathrm{R}^{2}=0.999 ; \quad \mathrm{LOD}=0.026 \mathrm{mg} \mathrm{L}^{-1} \mathrm{ZnO} \quad \mathrm{LOQ}=0.028 \mathrm{mg} \mathrm{L}^{-1}$ $\mathrm{ZnO}$.

ICP-MS data, readings done for ${ }^{66} \mathrm{Zn}$, calibration curve: $\mathrm{y}=1155452.6 \mathrm{x}-369.9$ $\mathrm{R}^{2}=0.9998 ; \quad \mathrm{LOD}=0.010 \mathrm{mg} \mathrm{L}^{-1} \pm 0.004 \mathrm{mg} \mathrm{L}^{-1} \quad$ of $\quad \mathrm{Zn}$, $\mathrm{LOQ}=0.030 \mathrm{mg} \mathrm{L}^{-1} \pm 0.005 \mathrm{mg} \mathrm{L}^{-1}$ of $\mathrm{Zn}$. All measurements were performed with a $4.3 \mathrm{~mL} \mathrm{~min}^{-1}$ Helium flow (Helium mode, for removing polyatomic interferences.

analyses times usually longer than those observed for AF4. To separate all type of suspensions by AF4, likely membranes of different chemical composition need to be tested (e.g. polyethersulfone, cellulose triacetate, PVDF membranes are available). Still, from an instrumental point of view, the presence of different detectors on-line (UV-vis, MALS or DLS) for both techniques, guarantees the undisputed advantage of collecting particle size information independently of potentially biased retention time data, especially when the sample behaviour deviates from the ideality because of possible reciprocal particle interactions or possible interactions with the channel walls. The observation that, being sample equal, the average sizes measured by AF4-MALS were always smaller than those determined through CF3-MALS, suggests the complementary of the FFF-techniques in dealing samples extremely heterogeneous in sizes. While AF4 is preferred when it comes to the characterization of the smaller fractions of the sample, CF3 is more suited for the larger aggregates, although this may lead to very long separation runs. However, CF3 revealed to be the more robust technique for the analysis of $\mathrm{ZnO}$ particles in cosmetic products in comparison to AF4, and the smallest $\mathrm{ZnO}$ particles $(\mathrm{d}<30 \mathrm{~nm})$, unfractionated in these experiments by CF3, could be correctly fractionated by increasing the field strength and modifying the field program.

\section{Funding}

This research was financially supported by the University of Ferrara (FIR -Fondo per l'Incentivazione alla Ricerca).

\section{Notes}

The authors declare no competing financial interest.

\section{Acknowledgements}

The authors gratefully thank Dr. Daniela Palmeri for her assistance during the SEM observations at the Centro di Microscopia Elettronica of the University of Ferrara; Dr. Valeria Disette for having formulated the cosmetic emulsions and the Dr. Antonella Pagnoni for having performed the ICP-OES measurements.

\section{Appendix A. Supplementary data}

Supplementary data associated with this article can be found, in the online version, at http://dx.doi.org/10.1016/j.chroma.2017.07.098.

\section{References}

[1] L.Z. Wang, Novel nanostructures of $\mathrm{ZnO}$ for nanoscale photonics, optoelectronics, piezoelectricity, and sensing, Appl. Phys. A 88 (1) (2007) 7-15.

[2] R.H. Fernando, Nanocomposite and nanostructured coatings recent advancements, ACS Symposium Series, American Chemical Society, Washington, DC, 20092-20

[3] G. Osmond, Zinc white: a review of zinc oxide pigment properties and implications for stability in oil-based paintings, AICCM Bull. 33 (2012) 20-29.

[4] C. Clementi, F. Rosi, A. Romani, R. Vivani, B.G. Brunetti, C. Miliani, Photoluminescence properties of zinc oxide in paints: a study of the effect of self-absorption and passivation, Appl. Spectrosc. 66 (10) (2012) 1233-1241.

[5] J. Pasquet, Y. Chevalier, E. Couval, D. Bouvier, M.-A. Bolzinger, Zinc oxide as a new antimicrobial preservative of topical products: interactions with common formulation ingredients, J. Pharm. 479 (2015) 88-95.

[6] H.M.C. de Azeredo, Antimicrobial nanostructures in food packaging, Trends Food Sci. Technol. 30 (1) (2013) 56-69.

[7] CS/1489/12 - Revision of 11 December 2012 Scientific Committee on Consumer Safety - SCCS OPINION ON Zinc oxide (nano form) COLIPA S 76. Addendum to the opinion SCCS/1489/12 on zinc oxide (nano form), 2014. http://ec. europa.eu/health/scientific_committees/consumer_safety/docs/sccs_o_137.pdf. (Accessed 2 May 2017).

[8] COMMISSION REGULATION (EU) 2016/621 of 21 April 2016 - Official Journal of the European Union, L 106 Volume 5922 April 2016, ISSN 1977-0677.

[9] Evaluation of the health aspects of certain zinc salts as food ingredients, PB 266879 Report prepared for Bureau of Foods Food and Drug Administration Department of Health, Education, and Welfare, Washington, D.C., November 1973.

[10] Scientific opinion, Safety assessment of the substance zinc oxide, nanoparticles, for use in food contact materials - EFSA Panel on Food Contact Materials, Enzymes, Flavourings and Processing Aids (CEF), EFSA J. 14 (3) (2016) 4408, https://doi.org/10.2903/j.efsa.2016.4408, (8 pp.).

[11] T. Linsinger, G. Roebben, D. Gilliland, L. Calzolai, F. Rossi, N. Gibson, C. Klein, Requirements on measurements for the implementation of the European Commission definition of the term nanomaterial, JRC (2012).

[12] K.M. Tyner, A.M. Wokovich, W.H. Doub, L.F. Buhse, L.-P. Sung, S.S. Watson, N. Sadrieh, Comparing methods for detecting and characterizing metal oxide nanoparticles in unmodified commercial sunscreens, Nanomedicine 4 (2) (2009) $145-159$.

[13] M.J. Osmond, M.J. McCall, Zinc oxide nanoparticles in modern sunscreens: an analysis of potential exposure and hazard, Nanotoxicology 4 (1) (2010) 15-41.

[14] C. Contado, Nanomaterials in consumer products: a challenging analytical problem, Front. Chem. 3 (2015) 48-67, https://doi.org/10.3389/fchem.2015.00048.

[15] Scientific Committee on Consumer Safety, Guidance on the safety assessment of nanomaterials in cosmetics, 2012, (Available at: http://ec.europa.eu/health/ scientific_committees/consumer_safety/docs/sccs_s_005.pdf).

[16] Pei-Jia Lu, Shou-Chieh Huang, Y̌u-Pen Chen, Lih-Ching Chiueh, Daniel Yang-Chih Shih, Analysis of titanium dioxide and zinc oxide nanoparticles in cosmetics, JFDA 23 (3) (2015) 587-594.

[17] C. Contado, A. Pagnoni, $\mathrm{TiO}_{2}$ in commercial sunscreen lotion: flow field-flow fractionation and ICP-AES together for size analysis, Anal. Chem. 80 (19) (2008) 7594-7608

[18] C. Nagelreiter, C. Valenta, Size analysis of nanoparticles in commercial O/W sunscreen, Int. J. Pharm. 456 (2013) 517-519.

[19] V. Nischwitz, H. Goenaga-Infante, Improved sample preparation and quality control for the characterisation of titanium dioxide nanoparticles in sunscreens using flow field flow fractionation on-line with inductively coupled plasma mass spectrometry, J. Anal. At. Spectrom. 27 (2012) 1084-1092.

[20] M.E. Schimpf, K.D. Caldwell, J.C. Giddings, Field-Flow Fractionation Handbook, Wiley-Interscience, New York, 2000.

[21] C. Contado, L. Ravani, M. Passarella, Size characterization by sedimentation field flow fractionation of silica particles used as food additives, Anal. Chim. Acta 788 (2013) 183-192.

[22] J. Heroult, V. Nischwitz, D. Bartczak, H. Goenaga-Infante, The potential of asymmetric flow field-flow fractionation hyphenated to multiple detectors for the quantification and size estimation of silica nanoparticles in a food matrix, Anal. Bioanal. Chem. 406 (2014) 3919-3927.

[23] K. Loeschner, J. Navratilova, C. Købler, K. Mølhave, S. Wagner, F. von der Kammer, E.H. Larsen, Detection and characterization of silver nanoparticles in chicken meat by asymmetric flow field flow fractionation with detection by conventional or single particle ICP-MS, Anal. Bioanal. Chem. 405 (2013) 8185-8195. 
[24] K. Loeschner, J. Navratilova, R. Grombe, T.P. Linsinger, C. Købler, K. Mølhave, E.H. Larsen, In-house validation of a method for determination of silver nanoparticles in chicken meat based on asymmetric flow field-flow fractionation and inductively coupled plasma mass spectrometric detection, Food Chem. 181 (2015) 78-84

[25] Z. Kuklenyik, M.S. Gardner, B.A. Parks, D.M. Schieltz, J.C. Rees, L.G. McWilliams, Y.M. Williamson, J.L. Pirkle, J.R. Barr, Multivariate DoE optimization of asymmetric flow field flow fractionation coupled to quantitative LC-MS/MS for analysis of lipoprotein subclasses, Chromatography 2 (2015) 96-117.

[26] S.M. Majedi, H.K. Lee, B.C. Kelly, Chemometric analytical approach for the cloud point extraction and inductively coupled plasma mass spectrometric determination of zinc oxide nanoparticles in water samples, Anal. Chem. 84 (2012) 6546-6552.

[27] A.A. Keller, H. Wang, D. Zhou, H.S. Lenihan, B.J. Cardinale, R. Miller, Z. Ji, Stability and aggregation of metal oxide nanoparticles in natural aqueous matrices, Environ. Sci. Technol. 44 (2010) 1962-1967.

[28] A. Punnoose, K. Dodge, J.W. Rasmussen, J. Chess, D. Wingett, C. Anders, Cytotoxicity of $\mathrm{ZnO}$ nanoparticles can Be tailored by modifying their surface structure: a green chemistry approach for safer nanomaterials, ACS Sustain. Chem. Eng. 2 (7) (2014) 1666-1673.

[29] R.J. Hunter, Foundations of Colloid Science, second edition, Oxford University Press, 2001.

[30] N.J. Lowe, Sunscreens: Development: Evaluation, and Regulatory Aspects, second edition, CRC Press, 1996.

[31] R.A. French, A.R. Jacobson, B. Kim, S.L. Isley, R.L. Penn, P.C. Baveye, Influence of ionic strength, $\mathrm{pH}$, and cation valence on aggregation kinetics of titanium dioxide nanoparticles, Environ. Sci. Technol. 43 (2009) 1354-1359.

[32] F.M. Omar, H.A. Aziz, S. Stoll, Stability of $\mathrm{ZnO}$ nanoparticles in solution. influence of $\mathrm{pH}$, dissolution, aggregation and disaggregation effects, J. Colloid Sci. Biotechnol. 3 (1) (2014) 1-10.

[33] C.F. Bohren, D.R. Huffman, Absorption and Scattering of Light by Small Particles, J. Wiley \& Sons, New York, 1983.

[34] T.L. Farias, U.Ö. Köylü, M.G. Carvalho, Range of validity of the Rayleigh-Debye-Gans theory for optics of fractal aggregates, Appl. Opt. 35 (33) (1996) 6560-6567.

[35] P.W. Barber, D.S. Wang, Rayleigh-Gans-Debye applicability to scattering by nonspherical particles, Appl. Opt. 17 (5) (1978) 797-803.

[36] J.C. Giddings, F.J.F. Yang, M.N. Myers, Sedimentation field-flow fractionation, Anal. Chem. 46 (13) (1974) 1917-1924.

[37] A.K. Brewer, A.M. Striegel, Characterizing the size, shape, and compactness of a polydisperse prolate ellipsoidal particle via quadruple-detector hydrodynamic chromatography, Analyst 136 (2011) 515-519.
[38] C. Contado, Field flow fractionation techniques to explore the nano-world, Anal. Bioanal. Chem. 409 (10) (2017) 2501-2518.

[39] B. Meisterjahn, S. Wagner, F. von der Kammer, D. Hennecke, T. Hofmann, Silver and gold nanoparticle separation using asymmetrical flow-field flow fractionation: influence of run conditions and of particle and membrane charges, J. Chromatogr. A 1440 (2016) 150-159.

[40] J. Gigault, T.M. Nguyen, J.M. Pettibone, V.A. Hackley, Accurate determination of the size distribution for polydisperse, cationic metallic nanomaterials by asymmetric-flow field flow fractionation, J. Nanopart. Res. 16 (2014) 2735-2744.

[41] I.C. Regelink, L. Weng, G.F. Koopmans, W.H. van Riemsdijk, Asymmetric flow field-flow fractionation as a new approach to analyse iron-(hydr)oxide nanoparticles in soil extracts, Geoderma 202-203 (2013) 134-141.

[42] O. Geiss, C. Cascio, D. Gilliland, F. Franchini, J. Barrero-Moreno, Size and mass determination of silver nanoparticles in an aqueous matrix using asymmetric flow field flow fractionation coupled to inductively coupled plasma mass spectrometer and ultraviolet-visible detectors, J. Chromatogr. A 1321 (2013) $100-108$.

[43] F. Barahona, O. Geiss, P. Urbán, I. Ojea-Jimenez, D. Gilliland, J. Barrero-Moreno, Simultaneous determination of size and quantification of silica nanoparticles by asymmetric flow field-flow fractionation coupled to ICPMS using silica nanoparticles standards, Anal. Chem. 87 (2015) 3039-3047.

[44] R.J.B. Peters, G. van Bemmel, Z. Herrera-Rivera, H.P.F.G. Helsper, H.J.P. Marvin, S. Weigel, P.C. Tromp, A.G. Oomen, A.G. Rietveld, H. Bouwmeester, Characterization of titanium dioxide nanoparticles in food products: analytical methods to define nanoparticles, J. Agric. Food Chem. 62 (2014) 6285-6293.

[45] Formulation and characterization of sunscreen creams with synergyistic efficacy on SPF by combination of UV filters, J. Appl. Pharm. Sci. 3 (8) (2013) 1-5.

[46] D. Fairhurst, An overview of physical (Particulate) sunscreens, in: H.G. Merkus, G.M.H. Meesters (Eds.), Particulate Products: Tailoring Properties for Optimal Performance, Particle Technology Series, Springer, 2013, (Cap. 14).

47]. C. Cascio, O. Geiss, F. Franchini, I. Ojea-Jimenez, F. Rossi, D. Gilliland, L. Calzolai, Detection, quantification and derivation of number size distribution of silver nanoparticles in antimicrobial consumer products, J. Anal. At. Spectrom. 30 (2015) 1255-1265.

[48] I. López-Heras, Y. Madrid, C. Cámara, Prospects and difficulties in $\mathrm{TiO}_{2}$ nanoparticles analysis in cosmetic and food products using asymmetrical flow field-flow fractionation hyphenated to inductively coupled plasma mass spectrometry, Talanta 124 (2014) 71-78. 